\title{
Application of CFD in building performance simulation for the outdoor environment: an overview
}

\author{
Bert Blocken* $^{(a)}$, Ted Stathopoulos ${ }^{(b)}$, Jan Carmeliet ${ }^{(\mathrm{c}, \mathrm{d})}$, Jan Hensen ${ }^{(\mathrm{e})}$
}

(a) Building Physics and Systems, Eindhoven University of Technology, P.O. box 513, 5600 MB

Eindhoven, The Netherlands, b.j.e.blocken@tue.nl

(b) Centre for Building Studies, Department of Building, Civil and Environmental Engineering, Concordia University, 1455 de Maisonneuve Blvd West, H3G 1M8, Montreal, Quebec, Canada, statho@bcee.concordia.ca

(c) Chair of Building Physics, Swiss Federal Institute of Technology ETHZ, ETH-Hönggerberg, CH8093 Zürich, Switzerland, carmeliet@arch.ethz.ch

(d) Laboratory for Building Science and Technologies, Empa, Swiss Federal Laboratories for Materials Testing and Research, Überlandstrasse 129, CH-8600 Dübendorf, Switzerland, jan.carmeliet@empa.ch

(e) Building Physics and Systems, Eindhoven University of Technology, P.O. box 513, 5600 MB Eindhoven, The Netherlands, j.l.m.hensen@tue.nl

Corresponding author: Bert Blocken, Building Physics and Systems, Eindhoven University of Technology, P.O. box 513, 5600 MB Eindhoven, the Netherlands. Tel: +31 (0)40 247 2138, Fax: +31 (0)40 243 8595. E-mail address: b.j.e.blocken@tue.nl

This paper provides an overview of the application of CFD in building performance simulation for the outdoor environment, focused on four topics: (1) pedestrian wind environment around buildings, (2) wind-driven rain on building facades, (3) convective heat transfer coefficients at exterior building surfaces, and (4) air pollutant dispersion around buildings. For each topic, its background, the need for CFD, an overview of some past CFD studies, a discussion about accuracy and some perspectives for practical application are provided. The paper indicates that for all four topics, CFD offers considerable advantages compared to wind tunnel modelling or (semi-)empirical formulae because it can provide detailed whole-flow field data under fully controlled conditions and without similarity constraints. The main limitations are the deficiencies of steady RANS modelling, the increased complexity and computational expense of LES and the requirement of systematic and time-consuming CFD solution verification and validation studies.

Keywords: Computational Fluid Dynamics; wind comfort; wind-driven rain; surface transfer coefficients; air pollution; review

\footnotetext{
* Corresponding author: Bert Blocken, Building Physics and Systems, Eindhoven University of Technology, P.O. box 513, 5600 MB Eindhoven, the Netherlands. Tel: +31 (0)40 247 2138, Fax: +31 (0)40 243 8595. E-mail address: b.j.e.blocken@tue.nl
} 


\section{Introduction}

Building performance simulation involves the use of computational models of buildings and components thereof for prediction of future behaviour in terms of physical performance indicators (Hensen and Lamberts 2010). Different computational model categories can be distinguished, including Building Energy Simulation (BES), Building Envelope Heat-Air-Moisture transfer models (BE-HAM) and Computational Fluid Dynamics (CFD).

In the past decades, CFD has been studied intensively as a tool for evaluating the indoor environment of buildings and heat and mass transfer between the indoor environment and the building envelope (e.g. Nielsen 1974, 2004, Awbi 1991, Chen and Jiang 1992, Chen et al. 1995, Djunaedy et al. 2005, Chen 1997, 2009, Heiselberg 1996, Srebric et al. 1999, Bartak et al. 2002, Beausoleil-Morrison 2002, Hayashi et al. 2002, Sorensen and Nielsen 2003, Abanto et al. 2004, Hensen 2004, Kim et al. 2005, Loomans et al. 2008, Steeman et al. 2009a, 2009b). It has also been used extensively in research on wind flow and the related processes in the outdoor environment around buildings, including pedestrian wind comfort (e.g. Stathopoulos and Baskaran 1990, Richards et al. 2002, Blocken et al. 2004, Yoshie et al. 2007, Mochida and Lun 2008, Tominaga et al. 2008a, Blocken and Persoon 2009), wind-driven rain (WDR) on building facades (e.g. Choi 1993, Etyemezian et al. 2000, van Mook 2002, Blocken and Carmeliet 2004a, Tang and Davidson 2004, Briggen et al. 2009, Blocken et al. 2010a, 2010b), pollutant dispersion around buildings (e.g. Tominaga et al. 1997, Li and Stathopoulos 1997, Leitl et al. 1997, Meroney et al. 1999, Meroney 2004, Hanna et al. 2006, Blocken et al. 2008a, Gromke et al. 2008, Tominaga and Stathopoulos 2009), exterior building surface heat transfer (e.g. Blocken et al. 2009, Defraeye et al. 2010), natural ventilation of buildings (e.g. Jiang and Chen 2002, Jiang et al. 2003, Cook and Hunt 2003, Wright and Hargreaves 2006, Hu et al. 2008, Cook et al. 2008, Chen 2009, Costola et al. 2009, Norton et al. 2009, 2010a, van Hooff and Blocken 2010a, 2010b) and wind loading of buildings (e.g. Tamura et al. 1997, Stathopoulos 1997, Selvam 1997a, Tamura et al. 2008, Nozu et al. 2008). For both indoor and outdoor environment studies, the advances in computing performance and the development of efficient and powerful grid generation techniques and CFD solvers have led to the present situation in which CFD can technically be applied for case studies involving complex geometries and flow fields (Figure 1).

However, while the use of CFD in engineering practice is becoming quite well established for indoor environment applications, this is considerably less pronounced for outdoor environment applications. In complex case studies, wind environmental problems such as pedestrian wind nuisance and air pollutant dispersion are still typically investigated in atmospheric boundary layer wind tunnels (Stathopoulos 2002), while WDR exposure and convective heat transfer coefficients at exterior building surfaces are generally estimated from simplified empirical or semi-empirical formulae (Blocken and Carmeliet 2004a, 2010a, Palyvos 2008, Defraeye et al. 2010). An important disadvantage of wind tunnel measurements however is that usually only point measurements are obtained. Techniques such as Particle Image Velocimetry (PIV) and Laser-Induced Fluorescence (LIF) in principle allow planar or even full 3D data to be obtained, but the cost is considerably higher and application for complicated geometries can be hampered by laser-light shielding by the obstructions constituting the urban model. Another disadvantage is the required adherence to similarity criteria in reduced-scale testing. This can be a problem for, e.g., multi-phase flow problems and buoyant flows. Examples are WDR and pollutant dispersion studies. Empirical and semi-empirical formulae generally only provide a first, crude indication of the relevant parameters, often in averaged form (e.g., surfaceaveraged) or at a few discrete positions. Examples are the semi-empirical formulae for WDR intensities (Lacy 1965, Sanders 1996, Straube and Burnett 2000, Blocken and Carmeliet 2004a, 2010a, 2010b, ISO 2009) and the (semi-)empirical expressions for convective heat transfer coefficients (e.g. Sharples 1984, Loveday and Taki 1996, Liu and Harris 2007, Palyvos 2008). In addition, a recent study comparing validated CFD simulations with the two most commonly used semi-empirical WDR models identified some important physical deficiencies in these models (Blocken et al. 2010b). Also, a sensitivity study demonstrated the very large impact of changes in heat transfer coefficients and the related mass transfer coefficients on the drying behaviour of ceramic bricks in facades (Janssen et al. 2007a). The information provided by empirical and semi-empirical formulae is often also too simplified compared to the well-established building performance simulation tools in which this information is used, such as Building Envelope Heat-Air-Mass (BE-HAM) transfer tools and Building Energy Simulation (BES) software.

Numerical modelling with CFD can be a powerful alternative because it can avoid some of these limitations. It can provide detailed information on the relevant flow variables in the whole calculation domain ("whole-flow field data"), under well-controlled conditions and without similarity constraints. However, the accuracy of CFD is an important matter of concern. Care is required in the 
geometrical implementation of the model, in grid generation and in selecting proper solution strategies and parameters. The latter include choices between steady Reynolds-averaged Navier-Stokes (RANS), unsteady RANS (URANS), Large Eddy Simulation (LES) or hybrid URANS/LES, between different turbulence models or subgrid-scale turbulence models, discretisation schemes, etc. In addition, numerical and physical modelling errors need to be assessed by solution verification and validation studies.

This paper provides an overview of the application of CFD in building performance simulation for the outdoor environment, focused on four topics: (1) pedestrian wind environment around buildings, (2) WDR on building facades, (3) convective heat transfer coefficients at exterior building surfaces, and (4) air pollutant dispersion around buildings. These four topics were chosen for four reasons: (1) they represent cases of varying physical complexity (single-phase flow, multi-phase flow with particles, heat transfer and multi-component gas flow); (2) they are in practice most often addressed by traditional approaches; i.e. either wind tunnel experiments or (semi-)empirical formulae; (3) CFD has some specific advantages for these topics compared to the traditional approaches; and (4) CFD is currently at a state in which it can technically be applied for these topics. First, in section 2, the wind-flow pattern around an isolated building is briefly described and the early CFD simulations of wind flow around an isolated building are discussed, as they provided the basis for the later applications. Section 3 lists a number of best practice guideline documents for CFD that were developed in the past decade. The overview with focus on the four topics is presented in sections 4-7. The overview is not intended to cover all previous research efforts in each of these topics, but rather to highlight specific difficulties, advantages and disadvantages of CFD.

\section{CFD simulation of wind flow around an isolated building}

\subsection{Description of wind-flow pattern}

The wind-flow pattern around an isolated building is briefly discussed to support the explanations in the following sections. Figure 2 provides a schematic illustration of the wind-flow pattern. As the wind approaches the building, it gradually diverges. At the windward facade (not shown in figure), a stagnation point with maximum pressure is situated at approximately 60-70\% of the building height. From this point, the flow is deviated to the lower pressure zones of the facade: upwards, sidewards and downwards. The upward and sideward flow separate at the upwind facade edges, and create a separation bubble or recirculation zone characterised by low velocity and high turbulence intensity. Depending on the building dimensions and the turbulence of the oncoming flow, the separated flow can reattach to the side facades and roof (as illustrated in Figure 2 by the dotted reattachment lines). A considerable amount of air flows downwards from the stagnation point and produces a vortex at ground level (called the standing vortex, frontal vortex or horseshoe vortex). The main flow direction of the standing vortex near ground level is opposite to the direction of the approach flow. Where both flows meet, a stagnation point with low wind speed values exists at ground level, upstream of the building (not shown in figure). The standing vortex stretches out sideways and sweeps around the building corners creating corner streams with high wind speeds. At the leeward side of the building, an underpressure zone exists. As a result, backflow or recirculation flow occurs in a cavity zone that consists of vortices with horizontal and vertical axes (i.e. the near wake). The mean cavity reattachment line downstream of the building marks the end of the cavity zone. Beyond this location, the flow resumes its normal direction but wind speed stays low for a considerable distance behind the building (i.e. the far wake). It is important to note that Figure 2 only shows the mean wind-flow pattern, and that the actual flow pattern exhibits pronounced transient features, such as the build-up and collapse of the separation/recirculation bubbles and periodic vortex shedding in the wake. Figure 2 also only shows the mean wind-flow pattern for a single building. In multi-building configurations, the flow patterns can interact, yielding a higher complexity.

\subsection{CFD simulations}

CFD simulation of wind flow around buildings started with fundamental studies for isolated buildings, often with a cubical shape, to analyse the velocity and pressure fields (Vasilic-Melling 1977, Hanson et al. 1986, Paterson and Apelt, 1986, 1989, 1990, Murakami et al. 1987, 1990, 1992, Murakami and Mochida, 1988, 1989, Baskaran and Stathopoulos, 1989, 1992, Stathopoulos and Baskaran 1990, Murakami 1990a, 1990b, 1993, Baetke et al. 1990, Mochida et al. 1993). Together with later studies, they laid the foundations for the current best practice guidelines, by focusing on the importance of grid resolution (Murakami and Mochida 1989, Murakami 1990a, 1990b, Baskaran and Stathopoulos 1992), 
the influence of the boundary conditions on the numerical results (Murakami and Mochida 1989, Paterson and Apelt 1990, Baetke et al. 1990, Stathopoulos and Baskaran 1990, Baskaran and Stathopoulos 1992) and by comparing the performance of various types of turbulence models in steady RANS simulations (Baskaran and Stathopoulos 1989, Murakami et al. 1992, Murakami 1993, Mochida et al. 2002). Also comparisons of RANS versus LES were performed (Murakami et al. 1990, 1992, Murakami 1990b, 1993). Note that in steady RANS simulations, only the mean flow is solved, while all scales of turbulence are modelled (i.e., approximated). In LES on the other hand, the large and generally most important turbulent eddies are explicitly resolved, while only the eddies smaller than a user-defined filter are modelled. In the past, especially the deficiencies of using the steady RANS approach with the standard k- $\varepsilon$ model (Jones and Launder 1972) for wind flow around buildings were addressed. These include the stagnation point anomaly with overestimation of turbulent kinetic energy near the frontal corner and the resulting underestimation of the size of separation and recirculation regions on the roof and the side faces, and the underestimation of turbulent kinetic energy in the wake resulting in an overestimation of the size of the cavity zone and wake. Various revised linear and nonlinear k- $\varepsilon$ models and also second-moment closure models were developed and tested, and showed improved performance for several parts of the flow field (Baskaran and Stathopoulos 1989, Murakami et al. 1992, Murakami 1993, Wright et al. 2001, Mochida et al. 2002). However, the main limitation of steady RANS modelling remained: its incapability to model inherently transient features of the flow field such as separation and recirculation downstream of windward edges and vortex shedding in the wake. These features can be explicitly resolved by LES. While URANS has hardly been used to study wind flow around buildings, early applications of LES for this purpose were already made by Murakami et al. in 1987, and later (Murakami et al. 1990, 1992, Murakami 1990b). These studies illustrated the superior performance of LES compared to RANS. The studies mentioned above are not all studies that were performed for isolated buildings. But starting from the 1990s, supported by the previous studies and the increased computing performance and availability of CFD codes, fundamental studies gradually shifted their focus to multiple-building configurations, and also application studies were increasingly performed. The sensitivity of the CFD results to the wide range of computational parameters to be set by the user and the possibility of applying CFD in practice led to the development of best practice guidelines in the past decades, as discussed in the next section.

\section{Best practice guidelines}

In CFD simulations, a large number of choices needs to be made by the user. It is well-known that these choices can have a very large impact on the results. In a typical CFD simulation, the user has to choose the approximate equations describing the flow (steady RANS, URANS, LES or hybrid URANS/LES), the level of detail in the geometrical representation of the buildings, the size of the computational domain, the boundary conditions, the computational grid, the discretisation schemes, the initialisation data, the time step size and the iterative convergence criteria.

Already since the start of the application of CFD for outdoor environment studies in the late 70-ies and 80-ies, researchers have been testing the influence of these parameters on the results, which has provided a lot of valuable information (e.g. Murakami and Mochida 1989, Baetke et al. 1990, Stathopoulos and Baskaran 1990, Cowan et al. 1997, Hall 1997). However, this information was dispersed over a large number of individual publications in different journals, conference proceedings and reports. In 2000, the ERCOFTAC ${ }^{1}$ Special Interest Group on Quality and Trust in Industrial CFD published an extensive set of best practice guidelines for industrial CFD users (Casey and Wintergerste 2000). The guidelines were focused on RANS simulations. Although they were not specifically intended for building studies, many of these guidelines also apply for simulations in the built environment. Within the EC project ECORA ${ }^{2}$, Menter et al. (2002) published best practice guidelines based on the ERCOFTAC guidelines, but modified and extended specifically for CFD code validation. Within QNET-CFD ${ }^{3}$, the Thematic Area on Civil Construction and HVAC (Heating, Ventilating and Air-Conditioning) and the Thematic Area on the Environment presented some best practice advice for the CFD simulations of wind flow and dispersion (Scaperdas and Gilham 2004, Bartzis et al. 2004).

In 2004, Franke et al. (2004) compiled a set of specific recommendations for the use of CFD in wind engineering from a detailed review of the literature. It was published as a keynote contribution in the final proceedings of the European $\mathrm{COST}^{4}$ Action C14: Impact of Wind and Storm on City Life

\footnotetext{
${ }^{1}$ ERCOFTAC = European Research Community on Flow, Turbulence and Combustion

${ }^{2}$ ECORA = Evaluation of Computational Fluid Dynamic Methods for Reactor Safety Analysis

${ }^{3}$ QNET-CFD $=$ Network for Quality and Trust in the Industrial Application of CFD

${ }^{4} \mathrm{COST}=$ European Cooperation in Science and Technology
} 
and Built Environment. Later, Franke et al. (2007) considerably extended this paper into an extensive "Best Practice Guideline for the CFD simulation of flows in the urban environment", in the framework of the COST Action 732: Quality Assurance and Improvement of Microscale Meteorological Models. Like the ERCOFTAC guidelines, also these guidelines were primarily focused on steady RANS simulations, although also some limited information on URANS, LES and hybrid URANS/LES was provided.

In Japan, working groups of the Architectural Institute of Japan (AIJ) conducted extensive cross-comparisons between CFD simulation results and high-quality wind tunnel measurements to support the development of guidelines for practical CFD applications. Part of these efforts was reported by Yoshie et al. (2007). In 2008, Tominaga et al. (2008b) published the "AIJ guidelines for practical applications of CFD to pedestrian wind environment around buildings", and Tamura et al. (2008) wrote the "AIJ guide for numerical prediction of wind loads on buildings". While the former document focused on steady RANS simulations, the latter also considered LES, given the importance of timedependent analysis for wind loading of buildings and structures.

More generic and also very important best practice advice was provided by Jakeman et al. (2006) in the paper "Ten iterative steps in development and evaluation of environmental models".

Apart from these general guidelines, also a number of very specific guidelines were published, such as those for modelling equilibrium atmospheric boundary layers in computational domains. The problem concerns the unintended changes (called streamwise gradients or horizontal inhomogeneity) that can occur in the vertical profiles of mean wind speed and turbulence quantities as they travel from the inlet of the computational domain towards the modelled buildings. This problem can dramatically affect the quality of the results. This is caused by the inconsistency between the inlet boundary conditions, the wall functions, the computational grid and the turbulence model (Richards and Hoxey 1993, Blocken et al. 2007a). To solve this problem, Richards and Hoxey (1993) provided inlet profiles and wall boundary conditions that are consistent with the standard $\mathrm{k}-\varepsilon$ model. Their effort was focused on $\mathrm{z}_{0}$-type wall functions, i.e. wall functions in which the aerodynamic roughness length $\mathrm{z}_{0}$ is present as a roughness parameter. As many - commercial - CFD codes employ $\mathrm{k}_{\mathrm{S}}$-type wall functions, i.e. with the equivalent sand-grain roughness height $\mathrm{k}_{\mathrm{S}}$ as a roughness parameter, Blocken et al. (2007a) derived the specific relationships between $\mathrm{k}_{\mathrm{S}}$ and $\mathrm{z}_{0}$, for Fluent 6 and Ansys CFX, and demonstrated the importance of satisfying these relationships in CFD simulations of wind flow around buildings (Blocken et al. 2007b). It should be noted that $\mathrm{k}_{\mathrm{S}}$ is about one order of magnitude larger than $\mathrm{z}_{0}$ (Blocken et al. 2007a), and that not taking this into account can effectively destroy the accuracy of the CFD simulations. Hargreaves and Wright (2007) provided modifications to the wall functions in CFX to address the same problem. Yang et al. (2009) suggested new and more realistic inlet profiles for the turbulence quantities, to be used in combination with the $\mathrm{k}_{\mathrm{S}}-\mathrm{Z}_{0}$ relationships by Blocken et al. (2007a). Finally, Gorlé et al. (2009) demonstrated that further consistency with the inlet profiles by Yang et al. (2009) and the $\mathrm{k}_{\mathrm{S}}-\mathrm{Z}_{0}$ relationships by Blocken et al. (2007a) could be achieved by converting turbulence model constants in the standard k- $\varepsilon$ model into functions. Also all these efforts were focused on steady RANS simulations.

The establishment of these guidelines has been an important step towards more accurate and reliable CFD simulations. Note that, although several of the guideline documents mentioned above have been developed with focus on a particular topic (e.g., pedestrian-level wind conditions), most of the information is also applicable to the other topics that will be treated in the following sections in this paper.

\section{Pedestrian wind environment around buildings}

\subsection{Background}

High-rise buildings can introduce high wind speed at pedestrian level, which can lead to uncomfortable or even dangerous conditions. Wind discomfort and wind danger can be detrimental to the success of new buildings. Wise (1970) reports about shops that are left untenanted because of the windy environment which discouraged shoppers. Lawson and Penwarden (1975) report the death of two old ladies due to an unfortunate fall caused by high wind speed at the base of a tall building. Today, many urban authorities only grant a building permit for a new high-rise building after a wind comfort study has indicated that the negative consequences for the pedestrian wind environment remain limited. Note that a wind comfort study is generally performed by a combination of three types of information/data: (1) statistical meteorological information; (2) aerodynamic information; and (3) a comfort criterion. CFD or wind tunnel data can be used to provide part of the aerodynamic information. 


\subsection{CFD versus wind tunnel measurements}

Wind comfort studies require knowledge of at least the mean wind velocity vector field at pedestrian height $(z=1.75$ or $2 \mathrm{~m}$ ). This information can be obtained by wind tunnel modelling or by CFD. Wind tunnel tests are generally point measurements with Laser Doppler Anemometry (LDA) or Hot Wire Anemometry (HWA). In the past, also area techniques such as sand erosion (Beranek and van Koten 1979, Beranek 1982, 1984, Livesey et al. 1990, Richards et al. 2002) and infrared thermography (Yamada et al. 1996, Wu and Stathopoulos 1997, Sasaki et al. 1997) have been used. They are however considered less suitable to obtain accurate quantitative information. Instead, they can be used as part of a two-step approach: first an area technique is used to qualitatively indicate the most important problem locations, followed by accurate point measurements at these most important locations (Blocken and Carmeliet 2004b).

One of the main advantages of CFD in pedestrian-level wind comfort studies is avoiding this time-consuming two-step approach by providing whole-flow field data. In spite of its deficiencies, steady RANS modelling with the k- $\varepsilon$ model or with other turbulence models has become the most popular approach for pedestrian-level wind studies. Two main categories of studies can be distinguished: (1) fundamental studies, which are typically conducted for simple, generic building configurations to obtain insight in the flow behaviour, for parametric studies and for CFD validation, and (2) applied studies, which provide knowledge of the wind environmental conditions in specific and often much more complex case studies. Fundamental studies - beyond the case of the isolated building - were performed by several authors including Baskaran and Stathopoulos (1989), Bottema (1993), Baskaran and Kashef (1996), Franke and Frank (2005), Yoshie et al. (2007), Blocken et al. (2007b, 2008b), Blocken and Carmeliet (2008), Tominaga et al. (2008a) and Mochida and Lun (2008). Apart from these fundamental studies, also several CFD studies of pedestrian wind conditions in complex urban environments have been performed (Murakami 1990a, Gadilhe et al. 1993, Takakura et al. 1993, Stathopoulos and Baskaran 1996, Baskaran and Kashef 1996, He and Song 1999, Ferreira et al. 2002, Richards et al., 2002, Miles and Westbury 2002, Westbury et al. 2002, Hirsch et al. 2002, Blocken et al. 2004, Yoshie et al. 2007, Blocken and Carmeliet 2008, Blocken and Persoon 2009). Some of the computational grids and some typical presentations of results of these studies are shown in Figure 3. Almost all these studies were conducted with the steady RANS approach and a version of the k- $\varepsilon$ model. An exception is the study by He and Song (1999) who used LES.

\subsection{Accuracy of $C F D$}

Attempts to provide general statements about the accuracy of steady RANS CFD for pedestrian-level wind environment studies can easily be compromised by the presence of a combination of numerical errors (such as discretisation errors and iterative convergence errors) and physical modelling errors (by using steady RANS, a turbulence model, simplified boundary conditions, etc.). Statements on the accuracy of steady RANS with a certain turbulence model should therefore be based on CFD studies that have undergone solution verification, i.e. it should be proven that numerical errors are limited, so clear conclusions about the physical modelling errors can be made. Several studies have adopted this approach in their validation of CFD with wind tunnel measurements and on site measurements. A general observation from these studies is that the prediction accuracy is a pronounced function of the location in the flow pattern, and therefore of the wind direction. While several validation studies have been performed for multi-building configurations, at least two of those have provided conclusions on the accuracy of steady RANS CFD that can be generalized: the extensive validation study by Yoshie $e t$ al. (2007) for four different building and urban configurations and the validation study by Blocken and Carmeliet (2008). These two studies are discussed next.

In the framework of the development of the AIJ guideline for wind environment evaluation, Yoshie et al. (2007) reported validation studies for four different building and urban configurations (Figure 4): (1) an isolated square prism with ratio $\mathrm{L}: \mathrm{W}: \mathrm{H}=1: 1: 2$, (b) an idealized high-rise building surrounded by regularly spaced low-rise buildings, (c) building complexes in the actual urban area of Niigata, Japan, and (d) building complexes in the actual Shinjuku sub-central area in Tokyo, Japan. A view of the computational grids is also shown in Figure 4. In all four cases, the simulations were performed with steady RANS, combined with the standard k- $\varepsilon$ model or with revised k- $\varepsilon$ models, and compared with the results of wind tunnel experiments. Note that the simulations included a gridsensitivity analysis, careful application of the boundary conditions, higher-order discretisation schemes, a complete report of the computational settings and parameters and a detailed comparison with the wind tunnel measurements. This is required in order to support the validity of the conclusions. 
The simulations for the isolated building were made with the standard k- $\varepsilon$ model and with two revised k- $\varepsilon$ models: the Launder-Kato k- $\varepsilon$ model (Kato and Launder 1993) and the Renormalization Group (RNG) k- $\varepsilon$ model (Yakhot and Orszag 1986). Comparison of the standard k- $\varepsilon$ model results with the wind tunnel measurements showed that the amplification factor $U / U_{0}$ (which is the ratio of the local pedestrian-level wind speed $U$ to the wind speed $U_{0}$ that would occur at the same position without buildings) is generally predicted within an accuracy of $10 \%$ in the regions where $U / U_{0}>1$ (see Figure 5a). In the wake region behind the building however, where $\mathrm{U} / \mathrm{U}_{0}<1$, the predicted wind speed is generally significantly underestimated, at some locations by a factor 5 and more (Figure $5 \mathrm{a}$ ). The results of the other turbulence models showed a slight improvement in the high wind-speed regions, but worse results in the wake region (Figure 5b). The underestimations in the wake region are attributed to the underestimation of turbulent kinetic energy in the wake, due to the fact that steady RANS with turbulence models such as the k- $\varepsilon$ model is not capable of reproducing the vortex shedding in the wake of buildings (Yoshie et al. 2007, Tominaga et al. 2008a).

The simulations for the idealized high-rise building surrounded by low-rise buildings were made with the standard k- $\varepsilon$ model and the RNG k- $\varepsilon$ model. In the high wind-speed regions, the standard k- $\varepsilon$ model underestimated the wind tunnel results by about $15 \%$. In the lower wind speed regions, differences up to a factor 4 were found. The results of the RNG k- $\varepsilon$ model showed improved performance in the high wind speed regions, but again a deteriorated performance in the lower wind speed regions. Similar conclusions on the different performance in high versus low wind speed regions were found in the CFD study for the actual urban area in Niigata: in high wind speed regions, the predictions are generally within $20 \%$ of the measurements, while the wind speed in low wind speed regions is generally significantly underestimated, at some positions with a factor 5 or more. The comparisons for the fourth configuration, the Shinjuku sub-central area, confirmed the findings for the other configurations. While for all four studies, large discrepancies are found in the low wind speed regions, it should be noted that the high wind speed regions are those of interest for pedestrian-level wind studies. In these regions, steady RANS was shown to provide a good to very good accuracy (10$20 \%)$.

Blocken and Carmeliet (2008) performed steady RANS CFD simulations with the realizable k- $\varepsilon$ model (Shih et al. 1995) for three configurations of parallel buildings and compared the results with the sand-erosion wind tunnel experiments by Beranek (1982). Two of these comparisons are shown in Figure 6, yielding observations that are very similar to those by Yoshie et al. (2007): a close to very close agreement between CFD and wind tunnel measurements in the region of high $\mathrm{U} / \mathrm{U}_{0}$ (about $10 \%$ accuracy), and significant underestimations in the regions of lower $\mathrm{U} / \mathrm{U}_{0}$. The regions of high $\mathrm{U} / \mathrm{U}_{0}$ are the corner streams and the areas between the buildings in which pressure short-circuiting occurs (Blocken and Carmeliet 2008). Other results from the same study (not shown in Figure 6) indicate that also the high $\mathrm{U} / \mathrm{U}_{0}$ in the standing vortex is predicted with good accuracy by steady RANS CFD. Note that the standing vortex is only clearly visible for wind directions that are almost perpendicular to the long building facade. Regions of low $\mathrm{U} / \mathrm{U}_{0}$ do not only occur in the wake of the buildings, but are also found in the low-speed stagnation zone upstream of the buildings. Similar to the results by Yoshie et al. (2007), the underestimations in these regions can go up to a factor 5 or more. Note that also these simulations were based on grid-sensitivity analysis, careful application of the boundary conditions and higher order discretisation schemes. It should be noted that sand-erosion measurement results are generally considered to be less suitable for CFD validation, although in this study a very close agreement - both qualitatively and quantitatively - was found in the high $\mathrm{U} / \mathrm{U}_{0}$ region.

For assessing the accuracy of CFD for pedestrian-level wind studies, it is important to compare them not only with wind tunnel measurements - where the boundary conditions are generally well-known - but also with on-site measurements. However, CFD pedestrian-level wind studies in complex urban environments including a comparison with on-site measurements are very scarce. To the knowledge of the authors, only two such studies have been published: the study by Yoshie et al. (2007) for the Shinjuku Sub-central area in Tokyo (Figure 4d and 4h) and the study by Blocken and Persoon (2009) for the area around the multifunctional ArenA stadium in Amsterdam (Figure 3e-f). Although these measurements were quite limited, overall, the comparisons confirmed the conclusions made earlier, albeit that the discrepancies in the high wind speed regions can exceed $10 \%$.

\subsection{Practical applicability}

In spite of the very limited number of validation studies based on on-site measurements, CFD is gaining increasing acceptance as a tool for pedestrian-level wind studies. This has recently been confirmed by the publication of the new Dutch Wind Nuisance Standard, NEN8100 (NEN 2006, Willemsen and Wisse, 2007) that specifically allows the user to choose between wind tunnel testing 
and CFD for analysing the pedestrian wind environment. The standard also demands quality assurance, both for wind tunnel testing and for CFD. It should be noted that CFD solution verification and validation and complete reporting of the followed procedure are essential components of quality assurance. In practical situations and in case of complex urban environments, when measurements are often not available, CFD model validation should be performed for simpler configurations, the flow features of which show resemblance with those expected in the actual complex urban configuration (Oberkampf et al. 2004, Blocken et al., 2004, Franke et al., 2007, Yoshie et al., 2007, Blocken and Carmeliet, 2008, Tominaga et al., 2008a). Blocken and Carmeliet (2008) called this approach subconfiguration validation. For these simpler cases, wind tunnel measurement data are generally available in the literature. Note that steady RANS is the commonly used method, while LES is still considered out of reach for practical pedestrian-level wind studies in actual urban environments (Yoshie et al. 2007). This is mainly attributed to the much larger calculation time. For pedestrian-level wind studies, simulations need to be performed for many (e.g. 12 or 16) wind directions, and this needs to be repeated for configurations with remedial measures implemented (Yoshie et al. 2007).

Nevertheless, it is expected that the increase in computing power and speed together with the superior performance of LES will render it increasingly more attractive in the years to come.

\section{Wind-driven rain on building facades}

\subsection{Background}

WDR is one of the most important moisture sources affecting the hygrothermal performance and durability of building facades. Consequences of its destructive properties can take many forms. Moisture accumulation in porous materials can lead to rain water penetration (Day et al. 1955, Marsh 1977), frost damage (Price 1975, Stupart 1989, Maurenbrecher and Suter 1993, Franke et al. 1998), moisture induced salt migration (Price 1975, Franke et al. 1998), discolouration by efflorescence (Eldridge 1976, Franke et al. 1998), structural cracking due to thermal and moisture gradients (Franke et al. 1998), to mention just a few. WDR impact and runoff is also responsible for the appearance of surface soiling patterns on facades that have become characteristic for so many of our buildings (White 1967, Camuffo et al. 1982, Davidson et al. 2000). Assessing the intensity of WDR on building facades is complex, because it is influenced by a wide range of parameters: building geometry, environment topography, position on the building facade, wind speed, wind direction, turbulence intensity, rainfall intensity and raindrop-size distribution.

\subsection{CFD versus measurements and semi-empirical formulae}

Some important drawbacks of WDR measurements and semi-empirical formulae have been mentioned in Section 1. CFD could be a valuable alternative to avoid time-consuming and expensive experiments, and to provide more detailed and accurate information than (semi-)empirical formulae. To the knowledge of the authors, the first CFD simulations of WDR on buildings were made by Souster (1979). For a full historical overview of WDR research in building engineering up to 2003, the reader is referred to (Blocken and Carmeliet 2004a). Choi (1991, 1993, 1994a, 1994b) developed and applied a steady-state simulation technique for WDR. It consists of solving the wind-flow pattern and calculating the trajectories of raindrops in this pattern by solving their equation of motion (Lagrangian particle tracking). This technique allows determining the spatial distribution of WDR on building facades for given (fixed) values of the wind speed, the wind direction and the horizontal rainfall intensity. Later, Choi's simulation technique was extended into the time domain by Blocken and Carmeliet (2002, 2007a). Choi's technique (with and without the extension) has been applied by many researchers. Most of these CFD simulations were based on the steady RANS approach and a k- $\varepsilon$ turbulence model to provide closure.

\subsection{Accuracy of CFD}

Although validation is an essential part of such simulations, up to now, only a few validation attempts have been made. Hangan (1999) compared his CFD simulations with the WDR wind tunnel tests by Inculet and Surry (1994). CFD validation with on-site full-scale WDR measurements was performed by van Mook (2002), Blocken and Carmeliet (2002, 2004a, 2006, 2007b), Tang and Davidson (2004), Abuku et al. (2009) and Briggen et al. (2009). While some authors found significant discrepancies between simulations and measurements, others indicated a fair to good agreement. Three examples are given below. 
Validation studies of WDR for a low-rise building were first performed by Blocken and Carmeliet in 2002 and later extended by the same authors in 2006 and 2007 (Blocken and Carmeliet 2002, 2006, 2007b). WDR measurements were made at 9 positions on the facade of the low-rise VLIET test building during 1997-1999 and at 24 facade positions during 2002 (Figure 7a). Figure 7b illustrates contours of the catch ratio on the south-west facade after a rain event with south-west wind direction. The catch ratio is the ratio of the WDR sum at a certain position at the facade to the rainfall sum measured by a traditional rain gauge (i.e. the unobstructed rainfall sum falling on the ground). The three separate validation studies in (Blocken and Carmeliet 2007b) indicate deviations between CFD results and measurements that are $20 \%$ on average, but that can locally go up to $50 \%$ and more. Considering the complexity of turbulent wind flow around a building and WDR deposition on building surfaces, $20 \%$ is considered very good agreement. Several remarks are made here: (1) The CFD simulations were made on grids based on grid-sensitivity analysis, with second-order discretisation schemes and specific care was given to specification of the boundary conditions; (2) The measurement data for validation were carefully selected to minimize measurement errors; (3) A good to very good qualitative agreement (wetting patterns) was obtained; (4) The error percentages mentioned do not include the values on the west corner of the building that was in reality influenced by a row of trees that was not included in the model.

Tang and Davidson (2004) performed measurements and CFD simulations of WDR on the facades of the Cathedral of Learning in Pittsburg, US, to explain the surface soiling patterns on the facades (Figure 7c-d). WDR measurements were made at 16 locations for a period of 21 months. The CFD simulations were performed using the extended simulation method by Blocken and Carmeliet (2002). The deviations were on average $25 \%$. The higher deviations compared to the study by Blocken and Carmeliet (2007b) can be attributed to the larger geometrical complexity of the building and its high-rise character, as will be explained later. Figure 7e shows the catch ratio distribution for different reference wind speeds. For this type of building, $25 \%$ is considered a very good agreement.

Briggen et al. (2009) conducted WDR measurements and CFD simulations for the south-west facade of the monumental building Hunting Lodge Saint Hubertus in the Netherlands, to provide the boundary conditions for numerical BE-HAM transfer models to analyse the moisture related damage (Figure 7f). The grid was based on grid-sensitivity analysis, specific care was given to the boundary conditions and the measurement data for validation were carefully selected following the guidelines by Blocken and Carmeliet (2005). In spite of these efforts, very large discrepancies were found at the lower part of the south-west facade (up to more than a factor 2), while a fair to good agreement was found at the upper part (20\% on average) One set of results is shown in Figure $7 \mathrm{~g}$. The most likely reason for these discrepancies is the role of turbulent dispersion of raindrops, which was neglected in these studies. The effect of turbulent dispersion can be very different depending on the building geometry and the position on the building (Briggen et al. 2009). It can be especially important for the bottom part of high-rise buildings and when the reference wind speed is low. The reason is that in this case, the raindrop trajectories (without turbulent dispersion) close to the windward facade are almost vertical and parallel to the bottom part of the windward facade, and do not always impinge on the facade. Turbulent dispersion in the streamwise direction can cause these raindrops to deviate from their "mean" trajectory and to hit the facade anyway. This means that, when including turbulent dispersion, more rain will impinge on the lower part of the facade in reality than calculated with the CFD model. This statement is corroborated by an earlier study by Lakehal et al. (1995) who found that turbulent dispersion is an important factor increasing WDR on vertical walls in cases with weak upstream wind flow, such as in a street canyon.

\subsection{Practical applicability}

In spite of quite some research efforts, the application of CFD for WDR studies in practice has up to now remained very limited. A few authors provided specific guidelines for CFD WDR simulation (Choi, 1994a, 1994b, Blocken and Carmeliet, 2002, 2004b, 2006, Briggen et al., 2009). It should be noted that the guidelines mentioned in section 3 also apply for CFD WDR studies, as accurate calculation of the wind-flow pattern is the first step for successful WDR simulations. There are two main reasons for the current limited practical use of CFD for WDR studies: (1) the very timeconsuming character of Lagrangian particle tracking of raindrops, in which the entire building facade needs to be covered by a large number of raindrops. Lagrangian particle tracking implies solving the equation of motion of individual raindrops within the wind-flow field. Note that this wind-flow field is generally obtained with an Eulerian approach, i.e. not focusing on individual particles but on fixed positions in space. Lagrangian tracking needs to be performed for a large number of combinations of reference wind speed, wind direction and raindrop diameter. (2) The fact that steady RANS generally 
does not allow accurate modelling of turbulence fields around buildings, and therefore also not of turbulent dispersion of raindrops, which is important for calculating WDR intensities at the lower part of high-rise building facades. Accurate turbulent dispersion modelling would require transient simulations with LES or hybrid URANS/LES, which would require even more intensive Lagrangian particle tracking efforts. To alleviate these problems, it might be necessary to abandon the traditional "Eulerian-Lagrangian" framework in CFD WDR simulations, and to resort to "Eulerian-Eulerian" modelling instead, in which not only the wind-flow pattern, but also the WDR intensities are computed with an Eulerian approach. It implies that the rain phase, like the air phase, is treated as a continuum.

\section{Convective heat transfer coefficients at exterior building facades}

\subsection{Background}

Knowledge of exterior convective heat transfer coefficients (CHTCs) is important for investigating the thermal performance of single-glazed (historical) buildings (e.g. Sharples 1984), double-skin facades (e.g. Saelens et al. 2003), green houses, tent-like structures (e.g. He and Hoyano 2009), solar collectors (e.g. Sharples and Charlesworth 1998), solar chimneys, ventilated photovoltaic arrays (e.g. Charron and Athienitis 2006), etc. Information on the CHTC is also important for the analysis of wetting and drying of building components and the related damage processes. The reason is that it is often used to calculate the convective moisture transfer coefficient (CMTC) by assuming the Chilton-Colburn analogy (Chilton and Colburn 1934, Schwartz 1971), which is current practice in BE-HAM tools (e.g., Künzel 1994, Hens 1996, Janssen et al. 2007b, Blocken et al. 2007c, Scheffler 2008, Steeman et al. 2009a, 2009c). Determining the values of exterior CHTC across building facades is a difficult task, because they are a complex function of a wide range of parameters including building geometry, environment topography, wind speed, wind direction, turbulence intensity, surface roughness, texture and geometry, and moisture content.

\subsection{CFD versus measurements and (semi-)empirical correlations}

In the past, CHTCs for exterior building surfaces have been determined using wind tunnel measurements (e.g. Kelnhofer and Thomas 1976) and full-scale measurements (e.g. Ito et al. 1972, Sharples et al. 1984, Loveday and Taki 1996, Liu and Harris 2007), and many (semi-)empirical CHTC correlations have been provided (for a review, see Palyvos 2008). The main disvantages of these assessment methods have been mentioned in the introduction. CFD could be a valuable alternative to avoid time-consuming and expensive experiments, and to provide more detailed and accurate information than (semi-)empirical formulae.

\subsection{Accuracy of CFD}

However, while a large number of valuable experimental investigations have been conducted, the number of CFD analyses for exterior CHTC for buildings is very small (Emmel et al. 2007, Blocken et al. 2009, Defraeye et al. 2010). This might seem strange given the very large number of such CFD studies that have been conducted in other disciplines, such as mechanical and electronic engineering. The main reason for this is the extremely high computational requirements for these simulations for building applications. As opposed to most mechanical and electronic engineering applications, the Reynolds numbers in civil and building engineering are several orders of magnitude larger $\left(10^{5}-10^{7}\right)$. The higher the Reynolds number, the lower the thickness of the viscous sublayer and buffer layer in the boundary layer near the surface. The viscous sublayer and buffer layer determine to a large extent the convective surface resistance. For building applications, the thickness of the viscous sublayer can go down to $1 \mathrm{~mm}-100 \mu \mathrm{m}$ (Blocken et al. 2009, Defraeye et al. 2010). Accurate CFD modelling of convective heat transfer generally requires accurate modelling of each part of the boundary layer (i.e. low-Re number modelling). Validation studies based on a wind tunnel test showed RANS CFD results to have an accuracy of at least (and generally much better) than $10 \%$ for the windward facade of a cubic building (Blocken et al. 2009, Defraeye et al. 2010). Larger discrepancies were found for the other building facades and the roof. Some previous simulations (Emmel et al. 2007) were conducted using wall functions, in which the effect of the boundary layer is strongly simplified. It has been shown that using wall functions instead of low-Re number modelling can yield overestimations of the CHTC by up to $60 \%$ (Blocken et al. 2009). Accurate modelling of convective heat transfer generally requires at least a few cells in the viscous sublayer, which implies a dimensionless wall unit $\mathrm{z}^{+}$of about 1 . This yields very high-resolution grids with large differences between the largest (easily up to $100 \mathrm{~m}$ ) and 
smallest (down to $100 \mu \mathrm{m}$ ) length scales. Such high grid resolution gradients and very small cells slow down convergence, can inhibit convergence to be obtained with less-diffusive turbulence models such as second-moment closure models, and can even cause computer round-off errors to become important. To the knowledge of the authors, such simulations have up to now only been performed by Blocken et al. (2009) and Defraeye et al. (2010), but these authors did not go further than considering the windward facade(s) of a simple cubic building model (Figure 8a) due to the computational expense of this type of simulations and to the limitations of steady RANS modelling to reproduce the flow in the separation regions beyond the windward facade(s). Some results are shown in Figure 8b. Obtaining accurate results for other facades would require improved flow modelling, which can be achieved with hybrid URANS/LES or LES.

\subsection{Practical applicability}

This type of high-resolution CFD simulations is not very practical for actual cases of building simulation. Instead, specially-adapted wall functions need to be developed that can accurately take into account convective surface heat transfer. However, note that also in this case, strictly, grids with a relatively high resolution will still be needed $\left(30<\mathrm{z}^{+}<500\right)$. Therefore, accurate exterior building heat (and mass) transfer simulations with CFD are certainly not straightforward and might remain out of range for many practical building simulation efforts for a considerable time to come.

\section{Air pollutant dispersion around buildings}

\subsection{Background}

Outdoor air pollution is one of the major environmental problems today. It is associated with a broad spectrum of acute and chronic health effects (e.g. Brunekreef and Holgate 2002). In the built environment, both the outdoor exposure of pedestrians and the indoor exposure of building inhabitants are of concern (e.g. Petersen et al. 2002) (Figure 9). Outdoor and indoor air pollution are a main concern of building and air-conditioning engineers that design the ventilation inlets and outlets on building facades or roofs (Drivas and Shair 1974, ASHRAE 1999, 2007). Indoor air pollution by outdoor air pollutants can be caused by the re-ingestion of the contaminated exhaust air by the same building or by the intake of exhaust from other sources such as nearby buildings, street traffic, vehicle parking lots and loading docks and emergency generators (Smeaton et al. 1991). The precise prediction of pollutant concentration distributions on and near buildings is important for building design and evaluation. The same holds for concentrations in streets and on squares. The prediction of such concentrations however is a difficult task, especially in the urban environment. It does not only require the knowledge of air pollution meteorology and dispersion, it also requires knowledge of building aerodynamics because wind and buildings can strongly affect plume behaviour.

\subsection{CFD versus measurements and semi-empirical formulae}

Pollutant concentration distributions can be assessed by on-site measurements, wind tunnel measurements, (semi-)empirical formulae and CFD. Several on-site measurement campaigns have been performed in the past (e.g. Barad 1958, Wilson and Lamb 1994, Lazure et al. 2002, Stathopoulos et al. 2002 , 2004). They are very valuable because they are conducted in the real atmospheric boundary layer and provide information on the real complexity of the phenomenon, but they are also time-consuming, expensive, and not an option in the design stage of a new building or new urban area. Many wind tunnel experiments have been conducted in the past to better understand the mechanisms of windinduced pollutant dispersion (e.g. Halitsky 1963, Huber and Snyder 1982, Li and Meroney 1983, Saathoff et al. 1995, 1998, Leitl et al. 1997, Meroney et al. 1999, Stathopoulos et al., 2002, 2004). The drawbacks of wind tunnel tests however are that they can be time-consuming and costly, that they are not applicable for light wind conditions, and that scaling - similarity - can be a difficult issue. Semiempirical models, such as the Gaussian model (Turner 1970, Pasquill and Smith 1983) and the socalled ASHRAE models (Wilson and Lamb 1994, ASHRAE 1999, 2003) are relatively simple and easy-to-use, at the expense of limited applicability and less accurate estimates. The Gaussian model, in its original form, is not applicable when there are obstacles between the emission source and the receptor, and the ASHRAE models only evaluate the minimum dilution factor on the plume centreline. 


\subsection{CFD for dispersion around an isolated cubic building}

In the past two decades, a very large number of so-called micro-scale CFD simulations of pollutant dispersion around buildings and in urban areas have been conducted. Micro-scale generally refers to simulations with horizontal length scales smaller than $5 \mathrm{~km}$. These simulations can be divided into generic and applied studies. Many generic studies have focused on very simplified configurations, such as the isolated building (e.g. Li and Meroney 1983, Leitl et al. 1997, Selvam 1997b, Tominaga et al. 1997, Li and Stathopoulos 1997, Meroney et al. 1999, Tominaga and Stathopoulos 2007a, 2007b, 2009, Blocken et al. 2008a) and the idealized street canyon (e.g. Leitl and Meroney 1997, Chan et al. 2002, Baik and Kim 2002, Kim and Baik 2004, Gromke et al. 2008). These generic studies have proven to be very suitable for verification, validation and sensitivity analysis. The reason is that, even although both situations are strong simplifications of reality, the flow and dispersion processes involved are very complex and contain many of the salient features that are also present in complex urban environments. Apart from these generic studies, several applied studies have recently been performed. Some of these have included LES and RANS simulations of gas plume spreading in very large computational domains (e.g., Hanna et al. 2006, Patnaik et al. 2007, Löhner et al. 2008). However, the grid resolution (e.g. 2-6 m) in these studies was often much lower than in the generic studies (e.g. $0.1 \mathrm{~m})$. The lower resolution could compromise the prediction accuracy around individual buildings and close to the building surfaces, but it should however be noted that this was not the intention of these studies.

As opposed to the three previous topics described in this paper, where the body of literature is fairly limited, a very large body of research exists on CFD simulation of dispersion around buildings and in urban areas. For the purpose of discussion in this paper, only one case is considered: windinduced dispersion of low-momentum exhaust from a vent in the middle of the roof of an isolated cubic building. Apart from limiting the extent of this section, the reasons for this very narrow selection are: (1) in this case the focus is at the scale of the individual building (i.e. on pollution / contamination of air intake openings), which is most relevant for other research in building performance simulation (indoor environment). As mentioned above, the resolution in most studies in very large computational domains is often too low $(>2 \mathrm{~m})$ to allow accurate concentration predictions across individual building surfaces; (2) detailed experimental data are available for this case (Li and Meroney 1983); (3) several researchers independently performed CFD simulation and validation studies for this case (both with RANS and LES); (4) the influence of different RANS turbulence models and of the value of the turbulent Schmidt number (i.e. the ratio of turbulent viscosity to turbulent mass diffusivity) was analysed; (5) the results allow a clear identification of the main difficulties in CFD modelling of pollutant dispersion.

Figure 10 illustrates the situation by mean wind-velocity vectors and contours of the mean dimensionless concentration coefficient $\mathrm{K}$ in a vertical plane through the middle of the building. $\mathrm{K}$ is defined as $\mathrm{CU}_{\mathrm{H}} \mathrm{L}^{2} / \mathrm{Q}_{\mathrm{e}}$, where $\mathrm{C}$ is the mass fraction of the tracer gas, $\mathrm{U}_{\mathrm{H}}$ the undisturbed wind speed at roof height $(\mathrm{m} / \mathrm{s})$, L the size of the cubic building model $(\mathrm{m})$ and $\mathrm{Q}_{\mathrm{e}}$ the emission rate of the pollutant $\left(\mathrm{m}^{3} / \mathrm{s}\right)$. Figure 10 shows that the emitted pollutant is caught in the recirculation bubble and is advected to the upstream building edge. CFD simulations for this configuration have been performed by e.g. Wang (2006), Tominaga and Stathopoulos (2007a, 2008) and Blocken et al. (2008a). Figure 11a shows the wind tunnel results by Li and Meroney (1983) as contours of K on the roof. To numerically reproduce these experiments, Wang (2006) used the realizable k- $\varepsilon$ model and the Reynolds Stress Model (RSM; Launder et al. 1975) with a linear pressure-strain model and wall-reflection effects (Gibson and Launder 1978, Launder 1989). She employed two values of the turbulent Schmidt number: $\mathrm{Sc}_{\mathrm{t}}=0.3$ and $\mathrm{Sc}_{\mathrm{t}}=0.7$ and the QUICK discretisation scheme (Leonard 1979). The results are given in Figures $11 \mathrm{~b}-\mathrm{d}$. While the upstream advection could not be adequately predicted with the realizable k- $\varepsilon$ model, the results by the RSM are much better, although the lateral dispersion is underestimated by the simulations. Tominaga and Stathopoulos (2007a) tested different turbulence models, including the standard k- $\varepsilon$ model, the RNG k- $\varepsilon$ model and the realizable $\mathrm{k}-\varepsilon$ model, in combination with $\mathrm{Sc}_{\mathrm{t}}=0.3$, 0.7 and 1.0, and the QUICK discretisation scheme. Some of their results are given in Figure 11e-g. The standard k- $\varepsilon$ model could not predict the recirculation on the roof and the realizable k- $\varepsilon$ model underestimated it, but better predictions were obtained with the RNG k- $\varepsilon$ model, which showed the best agreement with wind tunnel experiments of the separation bubble. The standard k- $\varepsilon$ model did not predict upstream dispersion, while the results from the other models are quite close to the wind tunnel results. Nevertheless, the results still show underestimation of the lateral dispersion, which is clear by observing the concentrations near the side edges. Blocken et al. (2008a) tested the realizable k- $\varepsilon$ model and the RSM, for $\mathrm{Sc}_{\mathrm{t}}=0.2,0.3,0.5,0.7,1.0$, with second order upwind discretisation. Both turbulence 
models correctly predicted the upstream dispersion, with the best result for $\mathrm{Sc}_{\mathrm{t}}=0.7$, but the lateral underestimation of dispersion found by these authors was significantly more pronounced than that found by Wang (2006) and Tominaga and Stathopoulos (2007a) (Figure 11h). They attributed this partly to an underestimation of the approach flow turbulent kinetic energy due to horizontal inhomogeneity in the approach flow. The differences in the realizable k- $\varepsilon$ model results between Wang (2006) (no prediction of recirculation) and Tominaga and Stathopoulos (2007a) and Blocken et al. (2008a) are probably due to artificial diffusion and near-wall treatment limitations associated with the lower grid resolution in Wang's case (2006). Finally, Tominaga and Stathopoulos (2008) applied LES (Figure 11i) and showed that taking into account the unsteadiness of the separation bubble leads to a much better prediction of lateral dispersion and a much closer agreement with the wind tunnel experiments, although the numerical results are a little bit more diffusive.

\subsection{Accuracy of CFD and practical applicability}

A general conclusion from these and other generic studies is that the accuracy of pollutant dispersion modelling depends highly on the choice of computational parameters to be made by the user. Figure 11 shows that errors exceeding one order of magnitude can occur at some positions on the roof. Another general conclusion is that RANS simulations in combination with typical turbulent Schmidt numbers of 0.7-0.9 systematically provide too low lateral turbulent diffusion compared to wind tunnel testing. In the past, several authors have attributed this to the fact that steady RANS modelling cannot incorporate the inherently transient behaviour of separation and recirculation downstream of windward edges, and of von Karman vortex shedding in the wake, which are particularly important for pollutant dispersion (Leitl et al. 1997, Meroney et al. 1999, Blocken et al. 2008a). In many simulations, $\mathrm{Sc}_{\mathrm{t}}$ has been explicitly used as a tuning factor to compensate for these deficiencies of steady RANS modelling (e.g. Tominaga and Stathopoulos 2007b, Blocken et al. 2008a). Note that, while $\mathrm{Sc}_{\mathrm{t}}$ is generally taken as a constant, it has been shown to be a function of the flow field (e.g. Koeltzsch 2000). Tominaga and Stathopoulos (2007a, 2008) showed that LES modelling, which takes into account these transient features because it actually solves the large eddies in the flow, can strongly improve pollutant concentration predictions compared to steady RANS. This seems to indicate that LES modelling is a requirement for pollutant dispersion modelling, also in complex urban environments. This is certainly the case when unsteady releases have to be considered, and/or when concentration fluctuations are important. However, the computational demands associated with this are large. The statement by Yoshie et al. (2007) that LES is still out of reach for practical pedestrian-level wind studies may equally apply to pollutant dispersion modelling. Note that, up to now, and as mentioned before, even the very extensive LES modelling efforts in complex urban environments, supported by efficient grid generation techniques and parallel computing facilities, were performed with relatively low resolution ( $\geq 2 \mathrm{~m}$ ). The application of LES to practical dispersion problems in urban environments however is not only limited by increased model complexity and computational resources, but also by the lack of detailed validation and sensitivity studies. This is important because, as the model formulation increases in complexity, the likelihood of degrading the model's performance due to input data and model parameter uncertainty increases as well (Hanna 1989).

\section{Discussion}

In the previous sections, CFD studies of wind flow and related processes around isolated buildings and in some urban areas were discussed. The vast majority of these studies were performed with the steady RANS approach, while only a few employed LES. The issue raised in the introduction of this paper was the fact that the application of CFD in practical building performance simulation for the outdoor environment is at present rather limited, and that wind tunnel experiments or simplified (semi)empirical formulae are generally used instead. These issues are discussed below.

\subsection{The isolated building versus actual urban areas}

The atmospheric boundary-layer wind-flow pattern in an actual urban area is very complex. The flow around a simple isolated cubic building model however contains many of the salient features that are also present in the flow in actual urban areas. Partly because of this reason, CFD model development, verification and validation in the past three decades have mainly focused on the simplest generic case: the isolated cubic building model. This holds for studies of pedestrian-level wind conditions, exterior heat transfer coefficients and pollutant dispersion around buildings. It equally applies to studies of natural/hybrid ventilation and wind loading on buildings, which have not been discussed in this paper. 
Another main reason why CFD has focused on the isolated (cubic) building model is because also many previous wind tunnel experiments were performed for this simple model and that - as a result these data are available for CFD validation. Note that the focus on the isolated cubic building is not as pronounced for WDR studies, because WDR measurements are almost never performed in wind tunnels. This is due to the many practical limitations and difficulties involved (Inculet and Surry 1994, Blocken and Carmeliet 2004a). CFD simulations of WDR have therefore often been performed for models of real buildings, for which experimental data were available. Note however that these were generally also "isolated" buildings, i.e. buildings without significant disturbance of their wind-flow pattern by surrounding buildings.

The focus on the simple isolated (cubic) building has allowed researchers to clearly identify some important difficulties, advantages and disadvantages of CFD for various applications. For all four topics treated in this paper, the same main limitation of steady RANS CFD was noted: the inability to accurately reproduce the flow field downstream of the windward facade, i.e. in the separation and wake regions that are inherently transient and characterised by low-velocity recirculations. In multi-building configurations and in urban areas, however, the presence of buildings downstream of others is a standard situation. The conclusions of steady RANS CFD validation studies that steady RANS CFD can provide good predictions of mean wind velocity patterns in high wind speed regions and of convective heat transfer coefficients and WDR on the windward facades of isolated buildings can not directly be extrapolated to multi-building configurations and urban areas without additional and detailed validation studies.

\subsection{RANS versus LES}

The majority of CFD studies in the four topics treated in this paper have employed steady RANS modelling. Some studies have explored the use of LES. Studies that have employed unsteady RANS (URANS) are very scarce. Franke et al. (2007) state that, since URANS also requires a high spatial resolution, it is recommended to directly use Detached Eddy Simulation (DES) or LES. Regardless of spatial resolution, it is important to note that URANS does not simulate the turbulence, but only its statistics. In fact, URANS only resolves the unsteady mean-flow structures, while it models the turbulence. LES on the other hand actually resolves the large scales of the turbulence. URANS can be a good option when the unsteadiness is pronounced and deterministic, such as von Karman vortex shedding in the wake of an obstacle with a low-turbulence approach flow. However, given the relatively high turbulence in (approach-flow) atmospheric boundary layers, DES or LES should be preferred over URANS for these applications.

As mentioned in the previous section, a main limitation of steady RANS is that it cannot incorporate the inherently transient behaviour of separation and recirculation downstream of windward edges, and of von Karman vortex shedding in the wake. As a result, the potential accuracy of LES is clearly superior. However, simulations with LES are considerably more complex than their steady RANS counterparts. LES requires specific time and space resolved inlet boundary condition data, specific grid distributions, temporal resolutions, sampling times, etc. There is still a lack of detailed validation and sensitivity studies for LES for atmospheric boundary layer flows. Note that there are quite some best practice documents for steady RANS simulations for the outdoor environment around buildings (see section 3), but that this is, at least at present, not the case for LES. In addition, LES evidently is much more time-consuming than RANS.

\subsection{CFD versus experiments for practical building applications}

At present, several important limitations are inhibiting the successful and systematic application of CFD in building performance simulation for the outdoor environment. They are generally related to either accuracy, or computational storage, or time, or a combination of these.

1. Computational domains for outdoor environment studies can be very large and the boundary conditions are generally not well-known. Earlier studies have shown that even the most basic case, CFD simulation of an equilibrium atmospheric boundary layer in an empty domain, is not straightforward (Blocken et al. 2007a, 2007b, Yang et al. 2009, Gorlé et al. 2009) and that this can introduce very large errors in simulation results (Blocken et al. 2007b).

2. Performing CFD simulations according to best practice guidelines, to ensure accuracy and reliability, can be very time-consuming. It requires solution verification and validation. The former includes grid-sensitivity analysis, i.e. multiple calculations for the same case on different grids. For validation, either earlier validation studies need to be consulted, or the user needs to perform his/her own validation studies to determine whether the selected set of 
simulation parameters can yield accurate results. In both cases, results from validation studies can easily be obscured by numerical errors. Without wanting to detract from the importance of the many validation studies that were and are conducted, the statement by Ferziger and Peric (1997) on turbulence model evaluation is mentioned below. While this statement was made more than a decade ago, it is still believed to be true today:

"Which model is best for which kind of flows (none is expected to be good for all flows) is not yet quite clear, partly due to the fact that in many attempts to answer this question numerical errors played a too important role so clear conclusions were not possible ... In most workshops held so far on the subject of evaluation of turbulence models, the differences between solutions produced by different authors using supposedly the same model were as large if not larger than the differences between the results of the same author using different models."

3. Even "best practice" steady RANS modelling can be insufficiently accurate, and in those cases the need to resort to LES will yield a strong increase in computer storage and computation times.

These limitations have contributed to the fact that the practical application of CFD in building performance simulation for the outdoor environment has so far remained quite limited. However, CFD has been applied successfully to specific case studies and in specific situations. CFD does have strong advantages, especially in the following types of studies:

1. Studies for which accurate wind tunnel experiments are very difficult or not possible (e.g. similarity issues for multi-phase flow, flow with thermal effects or for too extensive terrains);

2. Studies for which (semi-)empirical models are not applicable or do not provide sufficient accuracy;

3. Studies for which high-resolution or "whole-flow-field" data are requested; and

4. Studies in which the influence of a large number of small geometrical design changes need to be analysed.

For such studies, CFD has proven to be an indispensible building performance simulation tool. General examples are studies of WDR on buildings, buoyancy-induced natural ventilation of buildings and street canyons and wind environmental conditions for very large study areas. Some specific examples include WDR studies for rain shelter by roofs and canopies (e.g. Persoon et al. 2009, van Hooff et al. 2010) and for rain penetration and facade durability analysis (e.g. Etyemezian et al. 2000, Tang and Davidson 2004, Briggen et al. 2009), parametric studies for natural (buoyancy-driven) ventilation (e.g. van Hooff and Blocken 2010a, Norton et al. 2010b) and pollutant dispersion (e.g. Buccolieri et al. 2009). In addition, the combination of CFD and experiments can yield important synergetic effects: while experiments support CFD validation, CFD results can in turn be used to analyse and improve experimental set-ups, especially because it provides "whole-flow-field" data (e.g. Leitl and Meroney 1997, Moonen et al. 2006). It should also be noted that, instead of considering CFD as a primary tool for practical applications, it can also be used to support the derivation of new theoretical and semiempirical correlations, e.g. for WDR and CHTC.

In the studies for the four topics that were described in this paper, the inlet mean velocity and turbulence profiles were those corresponding to a neutral atmospheric boundary layer. Such mean velocity profiles are expressed by a logarithmic law or a power law. This approach corresponds to the traditional approach that is used in wind tunnels, in which generally also neutral atmospheric stability is assumed. Although "stratified" wind tunnels exist, dealing with atmospheric stratification can also be done in CFD. In particular, for cases in which the inlet conditions are determined by larger-scale meteorological phenomena, CFD can be coupled with mesoscale meteorological models (e.g. Mochida et al. 2010, Yamada 2010, Tominaga et al. 2010). This coupled approach can widely extend the applicability of CFD in building performance simulation for the outdoor environment, well beyond the limits of wind tunnel capabilities.

\section{Conclusions}

This paper has provided a state of the part overview of the application of CFD in building performance simulation for the outdoor environment, focused on four topics: (1) pedestrian wind environment around buildings, (2) wind-driven rain (WDR) on building facades, (3) convective heat transfer coefficients (CHTC) at exterior building surfaces, and (4) air pollutant dispersion around buildings. The overview was not intended to cover all previous research efforts for each of these topics, but rather 
to highlight specific difficulties, advantages and disadvantages of CFD for these topics. In addition, for each topic, its background, the need for CFD, an overview of past CFD studies, a discussion about accuracy and some perspectives for practical application have been provided. These four topics were chosen for four reasons: (1) they represent cases of varying physical complexity (single-phase flow, multi-phase flow with particles, heat transfer and multi-component gas flow); (2) they are in practice most often addressed by traditional approaches; i.e. either wind tunnel experiments or (semi-)empirical formulae; (3) CFD has some specific advantages for these topics compared to the traditional approaches; and (4) CFD is currently at a state in which it can technically applied for these topics. For each topic, some specific conclusions are presented below.

The wind tunnel is still considered as the standard tool for studying the pedestrian wind environment around buildings in practice. However, steady RANS CFD is gaining increased acceptance as a practical assessment tool, especially because it can provide whole-flow field data at a reasonable computational cost. This acceptance is supported by the availability of best practice guidelines for this specific type of application and by the results of detailed validation studies. These studies show that steady RANS can predict the mean velocity in high wind speed regions with a fairly good accuracy (10-20\%). These high wind speed regions are of most interest for pedestrian wind conditions. LES is potentially more accurate than steady RANS, but is much more computationally expensive.

The standard approach for the assessment of WDR on building facades is based on simplified semi-empirical formulae which can only provide rough estimates at a few discrete positions. Wind tunnel measurements are time-consuming and suffer from the required adherence to similarity criteria. CFD however can provide detailed whole-flow field data without similarity constraints. For isolated buildings, steady RANS CFD can predict the WDR intensities on low-rise building facades and at the upper part of high-rise building facades with an average accuracy of $20-25 \%$. For the lower part of high-rise buildings, modelling the turbulent dispersion of raindrops is important. This can be done by resolving the large-scale turbulence by LES. LES is also recommended for assessing WDR on non-isolated buildings (e.g. in urban environments), because of the deficiencies of steady RANS to accurately predict the wind-flow pattern downwind of the windward facade. To limit the computational cost, Eulerian modelling of the rain phase ("Eulerian-Eulerian modelling") should be preferred over Lagrangian modelling.

For CHTCs at exterior building surfaces, generally, empirical formulae are used. They only provide rough estimates at a few discrete positions. In CFD, resolving the lowest part of the boundary layer $(1 \mathrm{~mm}-100 \mu \mathrm{m})$, which represents the largest resistance to heat transfer, implies very small near-wall cells and high computational demands. If these can be met, steady RANS CFD with so-called low-Reynolds number modelling can predict the CHTC on the windward facade of an isolated building with an accuracy of $10 \%$. For assessing the CHTC on non-isolated buildings, the need for LES together with the required high grid resolution might yield excessive computational demands, which motivates the development of specially-adapted wall functions for this type of applications.

The standard approach for air pollutant dispersion around buildings is to either perform wind tunnel experiments at a few discrete positions or to obtain some rough estimates by applying (semi)empirical formulae. CFD can provide whole-flow field data without similarity constraints. The latter can be an issue for buoyant pollutants. Validation studies for the simple case of an isolated low-rise building with a rooftop vent indicate that the steady RANS CFD results are very sensitive to the turbulence model and to the value of the turbulent Schmidt number, which has often been used as a tuning parameter. For this case, even after tuning with the turbulent Schmidt number, steady RANS could not provide accurate predictions at all roof positions simultaneously. Steady RANS has also been found to underestimate the lateral diffusion, due to not modelling the inherently transient behaviour of the separation bubble. The resulting deviations between CFD simulations and experiments can go up to a factor 10 or more. Much better results can be obtained by LES, which seems to indicate that LES is a requirement for pollutant dispersion modelling, also in complex urban environments. This is certainly the case when unsteady releases have to be considered, and/or when concentration fluctuations are important.

For each of these four topics, CFD can be an indispensible tool that avoids specific shortcomings of measurements and simplified (semi-)empirical models. As illustrated in this paper, CFD has been used successfully in the past for a range of studies. Some main limitations are the deficiencies of steady RANS modelling, the time-consuming and significantly more complex character of LES, the need for high-resolution grids and the requirement of CFD solution verification and validation which can be very time-consuming. While the advances in computing performance and further research efforts will continue to alleviate some of these limitations, others (such as the required grid-sensitivity analysis) will remain. CFD will undoubtedly remain a tool of which the results should 
only be trusted if they have been obtained by skilled professionals that demonstrate the accuracy of their results by detailed solution verification and validation efforts.

Advancing the use of CFD in practice therefore imposes demands on the academic and research environments to increase and maintain high-quality education of CFD in building engineering disciplines. It also implies continued efforts to publicly provide high-quality wind tunnel and full-scale measurement data and validation studies, to demonstrate for which type of problems a certain set of computational parameters can provide accurate results. Such efforts will contribute to extend the current set of best practice guidelines, and to provide strong support to the use of CFD in building performance simulation of the outdoor environment.

\section{Acknowledgements}

Special thanks go to the many researchers with whom the authors had the pleasure of working in the past. Several of their important contributions to the literature have been cited in this paper, among with many other books and articles. In particular, the authors want to thank Prof. Yoshihide Tominaga of the Niigata Institute of Technology and Prof. Ryuichiro Yoshie of Tokyo Polytechnic University, for kindly providing permission to use their figure as figure 4 in this paper. The authors also thank Zara Huijbregts, PhD student at the Unit Building Physics and Systems of Eindhoven University of Technology, for preparing the modified figures 2 and 9.

The authors thank the anonymous reviewers for thoroughly reading the paper and for their very valuable comments.

The authors are also grateful for the permissions granted by Elsevier to reproduce the following figures:

Figure 1a: Reprinted from Building and Environment, 39(12), Abanto J, Barrero D, Reggio M, Ozell B, Airflow modelling in a computer room, pp. 1393-1402, Copyright (2004), with permission from Elsevier.

Figure 3a-b: Reprinted from Journal of Wind Engineering and Industrial Aerodynamics, 46-47, Gadilhe A, Janvier L, Barnaud G, Numerical and experimental modelling of the three-dimensional turbulent wind flow through an urban square, pp. 755-763, Copyright (1993), with permission from Elsevier.

Figure 3c-d: Reprinted from Journal of Wind Engineering and Industrial Aerodynamics, 81(1-3),

He J, Song CCS, Evaluation of pedestrian winds in urban area by numerical approach, pp. 295-309, Copyright (1999), with permission from Elsevier.

Figure 5: Reprinted from Journal of Wind Engineering and Industrial Aerodynamics, 95(9-11), Yoshie R, Mochida A, Tominaga Y, Kataoka H, Harimoto K, Nozu T, Shirasawa T, Cooperative project for CFD prediction of pedestrian wind environment in the Architectural Institute of Japan, pp. 1551-1578, Copyright (2007), with permission from Elsevier.

Figure 7d: Courtesy of Christopher Bailey (2010).

Figure 7e: Reprinted from Atmospheric Environment, 38(33), Wei Tang, Cliff I. Davidson, Erosion of limestone building surfaces caused by wind-driven rain: 2. Numerical modelling, pp. 5601-5609, Copyright (2004), with permission from Elsevier.

\section{References}

Abanto, J, Barrero, D, Reggio, M. and Ozell, B., 2004. Airflow modelling in a computer room. Building and Environment, 39 (12), 1393-1402.

Abuku, M., Blocken, B., Nore, K., Thue, J.V., Carmeliet, J. and Roels, S., 2009. On the validity of numerical wind-driven rain simulation on a rectangular low-rise building under various oblique winds. Building and Environment, 44 (3), 621- 632.

ASHRAE, 1999. Building air intake and exhaust design. Applications Handbook. Chapter 43.

ASHRAE, 2003. Building air intake and exhaust design. ASHRAE Application Handbook. Atlanta, (Chapter 44).

ASHRAE, 2007. Building air intake and exhaust design. Applications Handbook. Chapter 44.

Awbi, HB., 1991. Ventilation of buildings. Chapman \& Hall.

Baetke, F., Werner, H. and Wengle, H., 1990. Numerical simulation of turbulent flow over surfacemounted obstacles with sharp edges and corners. Journal of Wind Engineering and Industrial Aerodynamics, 35 (1-3), 129-147.

Baik, J.J. and Kim, J.J., 2002. On the escape of pollutants from urban street canyons. Atmospheric Environment, 36 (3), 527-536.

Bailey C. http://fatherpitt.wordpress.com 
Barad, M.L., 1958. Project prairie grass. A field program in diffusion. Geophysical Research Paper, No. 59, vols. I and II, Report AFCRC-TR-58-235. Air Force Cambridge Research Center, Bedford, MA.

Bartak, M., Beausoleil-Morrison, I., Clarke, J.A., Denev, J., Drkal, F., Lain, M., Macdonald, I.A., Melikov, A., Popiolek, Z. and Stankov, P., 2002. Integrating CFD and building simulation. Building and Environment, 37 (8-9), 865-871.

Bartzis, J.G., Vlachogiannis, D. and Sfetsos, A., 2004. Thematic area 5: Best practice advice for environmental flows. The QNET-CFD Network Newsletter 2 (4), 34-39.

Baskaran, A. and Kashef, A., 1996. Investigation of air flow around buildings using computational fluid dynamics techniques. Engineering Structures 18 (11), 861-873.

Baskaran, A. and Stathopoulos, T., 1989. Computational evaluation of wind effects on buildings. Building and Environment, 24 (4), 325-333.

Baskaran, A. and Stathopoulos, T., 1992. Influence of computational parameters on the evaluation of wind effects on the building envelope. Building and Environment, 27 (1), 39-49.

Beausoleil-Morrison I., 2002. The adaptive conflation of computational fluid dynamics with wholebuilding thermal simulation. Energy and Buildings, 34 (9), 857-871.

Beranek, W.J., 1982. Beperken van windhinder om gebouwen, deel 2, Stichting Bouwresearch no. 90, Kluwer Technische Boeken BV, Deventer (in Dutch).

Beranek, W.J., 1984. Wind environment around single buildings of rectangular shape, Heron, 29 (1), 4-31.

Beranek, W.J. and Van Koten, H., 1979. Beperken van windhinder om gebouwen, deel 1, Stichting Bouwresearch no. 65, Kluwer Technische Boeken BV, Deventer (in Dutch).

Blocken, B. and Carmeliet, J., 2002. Spatial and temporal distribution of driving rain on a low-rise building. Wind and Structures, 5 (5), 441-462.

Blocken, B., Carmeliet, J. 2004a. A review of wind-driven rain research in building science. Journal of Wind Engineering and Industrial Aerodynamics, 92 (13), 1079-1130.

Blocken, B., Carmeliet, J. 2004b. Pedestrian wind environment around buildings: Literature review and practical examples. Journal of Thermal Envelope and Building Science, 28 (2), 107-159.

Blocken, B., Roels, S., Carmeliet, J. 2004. Modification of pedestrian wind comfort in the Silvertop Tower passages by an automatic control system. Journal of Wind Engineering and Industrial Aerodynamics, 92 (10), 849-873.

Blocken B, Carmeliet J. 2005. High-resolution wind-driven rain measurements on a low-rise building experimental data for model development and model validation. Journal of Wind Engineering and Industrial Aerodynamics, 93 (12), 905-928.

Blocken, B. and Carmeliet, J., 2006. The influence of the wind-blocking effect by a building on its wind-driven rain exposure. Journal of Wind Engineering and Industrial Aerodynamics, 94 (2), 101-127.

Blocken, B., Stathopoulos, T. and Carmeliet, J., 2007a. CFD simulation of the atmospheric boundary layer: wall function problems. Atmospheric Environment, 41 (2) 238-252.

Blocken, B., Carmeliet, J. and Stathopoulos, T., 2007b. CFD evaluation of wind speed conditions in passages between parallel buildings - effect of wall-function roughness modifications for the atmospheric boundary layer flow. Journal of Wind Engineering and Industrial Aerodynamics, 95 (9-11), 941-962.

Blocken B, Roels S, Carmeliet J. 2007c. A combined CFD-HAM approach for wind-driven rain on building facades. Journal of Wind Engineering and Industrial Aerodynamics, 95 (7), 585-607.

Blocken, B, Carmeliet, J. 2007a. On the errors associated with the use of hourly data in wind-driven rain calculations on building facades. Atmospheric Environment, 41 (11), 2335-2343.

Blocken, B, Carmeliet, J. 2007b. Validation of CFD simulations of wind-driven rain on a low-rise building facade. Building and Environment, 42 (7), 2530-2548.

Blocken, B, Carmeliet, J. 2008. Pedestrian wind conditions at outdoor platforms in a high-rise apartment building: generic sub-configuration validation, wind comfort assessment and uncertainty issues. Wind and Structures, 11 (1), 51-70

Blocken, B, Stathopoulos, T, Saathoff, P, Wang, X. 2008a. Numerical evaluation of pollutant dispersion in the built environment: comparisons between models and experiments. Journal of Wind Engineering and Industrial Aerodynamics, 96 (10-11), 1817-1831.

Blocken, B, Moonen, P, Stathopoulos, T, Carmeliet, J. 2008b. A numerical study on the existence of the Venturi-effect in passages between perpendicular buildings. Journal of Engineering Mechanics - ASCE, 134 (12), 1021-1028. 
Blocken, B., Defraeye, T., Derome, D., Carmeliet, J. 2009. High-resolution CFD simulations for convective heat transfer coefficients at the facade of a low-rise building. Building and Environment, 44 (12), 2396-2412.

Blocken, B., Persoon, J., 2009. Pedestrian wind comfort around a large football stadium in an urban environment: CFD simulation, validation and application of the new Dutch wind nuisance standard. Journal of Wind Engineering and Industrial Aerodynamics, 97 (5-6), 255-270.

Blocken, B, Carmeliet J. 2010a. Overview of three state-of-the-art wind-driven rain assessment models and comparison based on model theory. Building and Environment, 45 (3), 691-703.

Blocken, B, Deszö, G, van Beeck, J, Carmeliet, J. 2010b. Comparison of calculation methods for winddriven rain deposition on building facades. Atmospheric Environment, 44 (14), 1714-1725.

Bottema, M., 1993. Wind climate and urban geometry. PhD thesis, Eindhoven University of Technology, 212p.

Briggen, P.M., Blocken, B., Schellen, H.L. 2009. Wind-driven rain on the facade of a monumental tower: numerical simulation, full-scale validation and sensitivity analysis. Building and Environment, 44 (8), 1675-1690.

Brunekreef, B., and Holgate, S.T., 2002. Air pollution and health. Lancet, 360 (9341), 1233-1242.

Buccolieri, R., Gromke, C., Di Sabatino, S., Ruck, B., 2009. Aerodynamic effects of trees on pollutant concentration in street canyons. The Science of the Total Environment, 407 (19), 5247-5256.

Camuffo, D., Del Monte, M., Sabbioni, C., Vittori, O., 1982. Wetting, deterioration and visual features of stone surfaces in an urban area, Atmospheric Environment, 16 (9), 2253-2259.

Casey, M., Wintergerste, T. 2000. Best Practice Guidelines, ERCOFTAC Special Interest Group on Quality and Trust in Industrial CFD, ERCOFTAC, Brussels.

Chan, TL, Dong, G., Leung, C.W., Cheung, C.S., Hung, T.W., 2002. Validation of a two-dimensional pollutant dispersion model in an isolated street canyon. Atmospheric Environment, 36 (5), 861872.

Charron R, Athienitis AK, 2006. Optimization of the performance of double-facades with integrated photovoltaic panels and motorized blinds. Solar Energy, 80 (5), 482-491.

Chen, Q, Jiang, Z. 1992. Significant questions in predicting room air motion. ASHRAE Transactions, 98 (1), 929-939.

Chen, Q, Peng, X, van Paassen, AHC. 1995. Prediction of room thermal response by CFD technique with conjugate heat transfer and radiation models. ASHRAE Transactions, 101 (2), 50-60.

Chen, Q. 1997. Computational fluid dynamics for HVAC - successes and failures. ASHRAE Transactions, 103 (1), 178-187.

Chen, QY. 2009. Ventilation performance prediction for buildings: A method overview and recent applications. Building and Environment, 44 (4), 848-858.

Chilton, TH, and Colburn, AP. 1934. Mass transfer (absorption) coefficients. Industrial and Engineering Chemistry, 26: 1183-1187.

Choi, E.C.C. 1991. Numerical simulation of wind-driven rain falling onto a 2-D building, in: Asia Pacific Conf. on Computational Mechanics, Hong Kong, 1721-1728.

Choi, E.C.C. 1993. Simulation of wind-driven rain around a building. Journal of Wind Engineering and Industrial Aerodynamics, 46\&47: 721-729.

Choi, E.C.C. 1994a. Determination of wind-driven rain intensity on building faces. Journal of Wind Engineering and Industrial Aerodynamics, 51: 55-69.

Choi, E.C.C. 1994b. Parameters affecting the intensity of wind-driven rain on the front face of a building. Journal of Wind Engineering and Industrial Aerodynamics, 53: 1-17.

Cook, MJ, Ji, Y, Hunt, GR. 2003. CFD modeling of natural ventilation: combined wind and buoyancy forces. International Journal of Ventilation, 1 (3), 169-80.

Cook, MJ, Zitzmann, T, Pfrommer, P. 2008. Dynamic thermal building analysis with CFD - modelling radiation. Journal of Building Performance Simulation, 1 (2), 117-131.

Costola D, Blocken B, Hensen JLM. 2009. Overview of pressure coefficient data in building energy simulation and airflow network programs. Building and Environment, 44 (10), 2027-2036.

Cowan, I.R., Castro, I.P., and Robins, A.G., 1997. Numerical considerations for simulations of flow and dispersion around buildings, Journal of Wind Engineering and Industrial Aerodynamics, 67 \& 68: 535-545.

Davidson, C.I., Tang, W., Finger, S., Etyemezian, V., Striegel, M.F., Sherwood, S.I., 2000. Soiling patterns on a tall limestone building: changes over 60 years, Environmental Science and Technology, 34 (4), 560-565.

Day, A.G., Lacy R.E., Skeen J.W., 1955. Rain penetration through walls, A summary of the investigations made at the UK Building Research Station from 1925 to 1955, Building Research Station Note. No. C.364, 1955, unpublished. 
Defraeye, T., Blocken, B., Carmeliet, J. 2009. CFD analysis of convective heat transfer at the surfaces of a cube in a deep turbulent boundary layer. International Journal of Heat and Mass Transfer, 53 (1-3), 297-308.

Djunaedy, E., Hensen, J.L.M., Loomans, M., 2005. External coupling between CFD and energy simulation: implementation and validation. ASHRAE Transactions, 109, 612-624.

Drivas, P.J. and Shair, F.H., 1974. Probing the air flow within the wake downwind of a building by means of a tracer technique. Atmospheric Environment, 8: 1165-1175.

Eldridge, H.J., 1976. Common defects in buildings, Her Majesty's Stationary Office, 486 p.

Emmel, M.G., Abadie, M.O., Mendes, N., 2007. New external convective heat transfer coefficient correlations for isolated low-rise buildings. Energy and Buildings, 39 (3), 335-342.

Etyemezian V, Davidson CI, Zufall M, Dai W, Finger S, Striegel M. 2000. Impingement of rain drops on a tall building. Atmospheric Environment, 34 (15), 2399-2412.

Ferreira, A.D., Sousa, A.C.M., Viegas, D.X. 2002. Prediction of building interference effects on pedestrian level comfort. Journal of Wind Engineering and Industrial Aerodynamics, 90 (4-5), 305-319.

Ferziger JH, Peric M. 1996. Computational methods for fluid dynamics. Springer Berlin, 356p.

Franke, J., Hirsch, C., Jensen, A.G., Krüs, H.W., Schatzmann, M., Westbury, P.S., Miles, S.D., Wisse, J.A., Wright, N.G., 2004. Recommendations on the use of CFD in wind engineering. In: van Beeck, J.P.A.J. (Ed.), Proceedings of the International Conference on Urban Wind Engineering and Building Aerodynamics. COST Action C14, Impact of Wind and Storm on City Life Built Environment. Von Karman Institute, Sint-Genesius-Rode, Belgium, 5-7 May 2004.

Franke, J., Frank, W., 2005. Numerical simulation of the flow across an asymmetric street intersection. In: Proceedings of the Fourth European and African Conference on Wind Engineering (4EACWE), 11-15 July 2005, Prague, Czech Republic.

Franke J. 2007. Guidelines and recommendations of good subject practice for the use of numeric flow mechanics in the wind engineering. Bauingenieur 82: S6-S8.

Franke, J., Hellsten, A., Schlünzen, H., Carissimo, B. (Eds.), 2007. Best practice guideline for the CFD simulation of flows in the urban environment. COST Office Brussels, ISBN 3-00-018312-4.

Franke, L., Schumann, I., van Hees, R., van der Klugt, L., Naldini, S., Binda, L., Baronio, G., Van Balen, K., Mateus, J., 1998. Damage atlas: classification and analyses of damage patterns found in brick masonry, European Commission Research Report No 8, vol. 2, Fraunhofer IRB Verlag, 1998.

Gadilhe, A., Janvier, L., Barnaud, G. 1993. Numerical and experimental modelling of the threedimensional turbulent wind flow through an urban square. Journal of Wind Engineering and Industrial Aerodynamics, 46-47: 755-763.

Gibson, M.M., Launder, B.E., 1978. Ground effects on pressure fluctuations in the atmospheric boundary layer. Journal of Fluid Mechanics 86, 491-511.

Gorlé, C., van Beeck, J., Rambaud, P., Van Tendeloo, G., 2009. CFD modelling of small particle dispersion: the influence of the turbulence kinetic energy in the atmospheric boundary layer. Atmospheric Environment, 43 (3), 673-681.

Gromke, C, Buccolieri, R, Di Sabatino, S, Ruck B., 2008. Dispersion study in a street canyon with tree planting by means of wind tunnel and numerical investigations - Evaluation of CFD data with experimental data. Atmospheric Environment, 42 (37), 8640-8650.

Guardo, A., Coussirat, M., Egusquiza, E., Alavedra, P., Castilla, R., 2009. A CFD approach to evaluate the influence of construction and operation parameters on the performance of Active Transparent Façades in Mediterranean climates. Energy and Buildings, 41 (5), 534-542.

Halitsky, J., 1963. Gas diffusion near buildings. ASHRAE Transactions, 69: 464-485.

Hall, R.C. (Ed.), 1997. Evaluation of modelling uncertainty. CFD modelling of near-field atmospheric dispersion. Project EMU final report, European Commission Directorate-General XII Science, Research and Development Contract EV5V-CT94- 0531, WS Atkins Consultants Ltd., Surrey.

Hangan, H., 1999. Wind-driven rain studies. A C-FD-E approach. Journal of Wind Engineering and Industrial Aerodynamics, 81: 323-331.

Hanna, S.R., 1989. Plume dispersion and concentration fluctuations in the atmosphere. Encyclopedia of Environmental Control Technology. In: Air Pollution Control, Vol. 2. Gulf Publishing Company, Houston, TX, pp. 547-582.

Hanna, S.R., Brown, M.J., Camell, F.E., Chan, S.T., Coirier, W.J., Hansen, O.R., Huber, A.H., Kim, S., Reynolds, R.M. 2006. Detailed simulations of atmospheric flow and dispersion in downtown Manhattan: An application of five computational fluid dynamics models. Bulletin of the American Meteorological Society, 87 (12), 1713. 
Hanson, T. Summers D.M., Wilson, C.B. 1986. Validation of a computer simulation of wind flow over a building model. Building and Environment, 21: 97-111.

Hargreaves, D.M., Wright, N.G. 2007. On the use of the k- $\varepsilon$ model in commercial CFD software to model the neutral atmospheric boundary layer. Journal of Wind Engineering and Industrial Aerodynamics, 95 (5), 355-369.

Hayashi, T, Ishizu, Y, Kato, S, Murakami, S. 2002. CFD analysis on characteristics of contaminated indoor air ventilation and its application in the evaluation of the effects of contaminant inhalation by a human occupant. Building and Environment, 37 (3), 219-230.

He, J., Song, C.C.S., 1999. Evaluation of pedestrian winds in urban area by numerical approach. Journal of Wind Engineering and Industrial Aerodynamics, 81, 295-309.

He J., Hoyano A., 2009. Measurement and simulation of the thermal environment in the built space under a membrane structure, Building and Environment, 44 (6), 1119-1127.

Heiselberg, P. 1996. Room air and contaminant distribution in mixed ventilation. ASHRAE Transactions, 102 (2), 332-339.

Hens, H. 1996. IEA Annex 24 Final Report Volume 1: Modelling, Acco Leuven, Belgium.

Hensen, JLM. 2004. Integrated building airflow simulation. in Advanced Building Simulation, A. Malkawi \& G. Augenbroe, eds., Spon Press, New York, pp. 87-118.

Hensen, J.L.M. and Lamberts, R. 2010. Building Performance Simulation for Design and Operation, Routledge, London.

Hirsch, C., Bouffioux, V., Wilquem, F. 2002. CFD simulation of the impact of new buildings on wind comfort in an urban area. Workshop Proceedings, Cost Action C14, Impact of Wind and Storm on City Life and Built Environment, Nantes, France.

Hosker, R.P., 1984. Flow and diffusion near obstacles. In: Randerson D. (Ed.), Atmospheric Science and Power Production, Office of Scientific and Technical Information, United States Department of Energy.

$\mathrm{Hu}, \mathrm{C}$, Ohba, M, Yoshie, R. 2008. CFD modelling of unsteady cross ventilation flows using LES. Journal of Wind Engineering and Industrial Aerodynamics, 96 (10-11), 1692-1706.

Huber, A.H., Snyder, W.H., 1982. Wind tunnel investigation of the effects of a rectangular shaped building on dispersion of effluent from short adjacent stacks. Atmospheric Environment, 16 (12), 2837-2848.

Inculet, D., Surry, D., 1994. Simulation of wind-driven rain and wetting patterns on buildings, BLWTLSS30-1994, Final report.

ISO, 2009. Hygrothermal performance of buildings - Calculation and presentation of climatic dataPart 3: Calculation of a driving rain index for vertical surfaces from hourly wind and rain data. ISO 15927-3:2009 International Organization for Standardization.

Ito, N., Kimura, K., Oka, J. 1972. A field experiment study on the convective heat transfer coefficient on exterior surface of a building. ASHRAE Transactions, 78: 184-191.

Jakeman, A.J., Letcher, R.A., Norton, J.P. 2006. Ten iterative steps in development and evaluation of environmental models. Environmental Modelling \& Software, 21 (5), 602-614.

Janssen, H, Blocken, B, Carmeliet, J. 2007a. Wind-driven rain as a boundary condition for HAM simulations: Analysis of simplified modelling approaches. Building and Environment, 42 (4), 1555-1567.

Janssen, H, Blocken, B, Carmeliet, J. 2007b. Conservative modelling of the moisture and heat transfer in building components under atmospheric excitation. International Journal of Heat and Mass Transfer, 50 (5-6), 1128-1140.

Jiang, Y, Chen, Q., 2002. Effect of fluctuating wind direction on cross natural ventilation in buildings from large eddy simulation. Building and Environment, 37 (4), 379-386.

Jiang, Y, Alexander, D, Jenkins, H, Arthur, R, Chen, Q. 2003. Natural ventilation in buildings: measurement in a wind tunnel and numerical simulation with large-eddy simulation. Journal of Wind Engineering and Industrial Aerodynamics, 91 (3), 331-353.

Jones, W.P., Launder, B.E., 1972. The prediction of laminarization with a 2-equation model of turbulence. International Journal of Heat and Mass Transfer, 15: 301.

Kato, M., Launder, B.E., 1993. The modelling of turbulent flow around stationary and vibrating square cylinders. In: Nineth Symposium on Turbulent Shear Flows, pp. 10-14.

Kelnhofer, W.J., Thomas C.J. 1976. External convection heat transfer coefficients on a building model. ASME Paper 76-WA/FE-30, ASME Winter Annual Meeting, New York.

Kim JJ, Baik JJ. 2004. A numerical study of the effects of ambient wind direction on flow and dispersion in urban street canyons using the RNG k-E turbulence model. Atmospheric Environment, 38 (19), 3039-3048. 
Kim, T, Kato, S, Murakami, S, Rho, J. 2005. Study on indoor thermal environment of office space controlled by cooling panel system using field measurement and the numerical simulation. Building and Environment, 40 (3), 301-310.

Koeltzsch, K. 2000. The height dependence of the turbulent Schmidt number within the boundary layer. Atmospheric Environment, 34: 1147-1151.

Künzel, H.M., 1994. Verfahren zur ein- und zweidimensionalen Berechnung des gekoppelten Wärmeund Feuchtetransoports in Bauteilen mit einfachen Kennwerten, $\mathrm{PhD}$ thesis, University of Stuttgart, Germany.

Lacy, RE. 1965. Driving-rain maps and the onslaught of rain on buildings. RILEM/CIB Symp. on Moisture Problems in Buildings, Rain Penetration, Helsinki; August 16-19, Vol. 3, paper 3-4.

Lakehal D., Mestayer P.G., Edson J.B., Anquetin S., Sini JF., 1995. Eulero-Lagrangian simulation of raindrop trajectories and impacts within the urban canopy. Atmospheric Environment, 29 (23), 3501-3517.

Launder, B.E., Reece, G.J., Rodi, W., 1975. Progress in the development of a Reynolds-stress turbulence closure. Journal of Fluid Mechanics, 68 (3), 537-566.

Launder, B.E., 1989. Second-moment closure and its use in modeling turbulent industrial flows. International Journal for Numerical Methods in Fluids, 9: 963-985.

Lawson, T.V., Penwarden, A.D. 1975. The effects of wind on people in the vicinity of buildings. $4^{\text {th }}$ Int. Conf. Wind Effects on Buildings and Structures, Heathrow.

Lazure, L., Saathoff, P., Stathopoulos, T., 2002. Air intake contamination by building exhausts: tracer gas investigation of atmospheric dispersion models in the urban environment. Journal of the Air Waste Management Association, 52: 160-166.

Leitl, B.M., Kastner-Klein, P., Rau, M., Meroney, R.N. 1997. Concentration and flow distributions in the vicinity of U-shaped buildings: wind-tunnel and computational data. Journal of Wind Engineering and Industrial Aerodynamics, 67\&68: 745-755.

Leitl, B.M., Meroney, R., 1997. Car exhaust dispersion in a street canyon. Numerical critique of a wind tunnel experiment. Journal of Wind Engineering and Industrial Aerodynamics, 67-68: 293-304.

Leonard, B.P., 1979. A stable and accurate convection modelling procedure based on quadratic upstream interpolation. Computer Methods in Applied Mechanics and Engineering, 19: 59-98.

Li, W., Meroney, R.N. 1983. Gas dispersion near a cubical model building. Part I. Mean concentration measurements. Journal of Wind Engineering and Industrial Aerodynamics, 12 (1), 15-33.

Li, Y., Stathopoulos, T. 1997. Numerical evaluation of wind-induced dispersion of pollutants around a building. Journal of Wind Engineering and Industrial Aerodynamics, 67\&68: 757-766.

Liu, Y, Harris, DJ. 2007. Full-scale measurements of convective coefficient on external surface of a low-rise building in sheltered conditions. Building and Environment, 42 (7), 2718-2736.

Livesey, F., Inculet, D., Isyumov, N. and Davenport, A.G., 1990. A Scour Technique for Evaluation of Pedestrian Winds, Journal of Wind Engineering and Industrial Aerodynamics, 36: 779-789.

Löhner, R., Cebral, J.R., Camelli, F.E., Appanaboyina, S., Baum, J.D., Mestreau, E.L., Soto, O.A., 2008. Adaptive embedded and immersed unstructured grid techniques. Computer Methods in Applied Mechanics and Engineering, 197 (25-28), 2173-2197.

Loomans, MGLC, van Houdt, W, Lemaire AD, Hensen JLM., 2008. Performance assessment of an operating theatre design using CFD simulation and tracer gas measurements. Indoor and Built Environment, 17 (4), 299-312.

Loveday, DL, Taki, AH, 1996. Convective heat transfer coefficients at a plane surface on a full-scale building facade. International Journal of Heat and Mass Transfer, 39 (8), 1729-1742.

Marsh, P. 1977. Air and rain penetration of buildings, The Construction Press Ltd., Lancaster, England, $174 \mathrm{p}$.

Maurenbrecher, A.H.P., Suter, G.T., 1993. Frost damage to clay brick in a loadbearing masonry building, Canadian Journal of Civil Engineering, 20: 247-253.

Meroney, R.N., Leitl, B.M., Rafailidis, S. and Schatzmann, M. 1999. Wind-tunnel and numerical modeling of flow and dispersion about several building shapes. Journal of Wind Engineering and Industrial Aerodynamics, 81: 333-345.

Meroney, R.N., 2004. Wind tunnel and numerical simulation of pollution dispersion: a hybrid approach. Working paper, Croucher Advanced Study Institute on Wind Tunnel Modeling, Hong Kong University of Science and Technology, 6-10 December, 2004, pp. 60.

Miles, S.D., Westbury, P.S. 2002. Assessing CFD as a tool for practical wind engineering applications. Proc. Fifth UK Conf. Wind Engineering, September.

Mochida, A., Iizuka, S., Tominaga, Y., Lun I.Y.F., 2010. Up-scaling CWE models to include mesoscale meteorological influences. The Fifth International Symposium on Computational Wind Engineering (CWE2010), Chapel Hill, North Carolina, USA, May 23-37. 
Moonen, P., Blocken, B., Roels, S., Carmeliet, J. 2006. Numerical modeling of the flow conditions in a low-speed closed-circuit wind tunnel. Journal of Wind Engineering and Industrial Aerodynamics, 94 (10), 699-723.

Murakami, S., Mochida, A., Hibi, K., 1987. Three-dimensional numerical simulation of airflow around a cubic model by means of large eddy simulation. Journal of Wind Engineering and Industrial Aerodynamics, 25: 291-305.

Murakami, S., Mochida, A., 1988. 3-D numerical simulation of airflow around a cubic model by means of the k- $\varepsilon$ model. Journal of Wind Engineering and Industrial Aerodynamics, 31 (2-3), 283-303.

Murakami S, Mochida A., 1989. Three-dimensional numerical simulation of turbulent flow around buildings using the $\mathrm{k}-\varepsilon$ turbulence model. Building and Environment, 24 (1), 51-64.

Murakami, S., 1990a. Computational wind engineering. Journal of Wind Engineering and Industrial Aerodynamics, 36 (1), 517-538.

Murakami, S., 1990b. Numerical simulation of turbulent flowfield around cubic model: current status and applications of k-e model and LES. Journal of Wind Engineering and Industrial Aerodynamics, 33 (1-2), 139-152.

Murakami, S, Mochida, A, Hayashi, Y. 1990. Examining the k- $\varepsilon$ model by means of a wind tunnel test and large-eddy simulation of the turbulence structure around a cube. Journal of Wind Engineering and Industrial Aerodynamics, 35: 87-100.

Murakami, S., Mochida, A., Hayashi, Y., Sakamoto, S. 1992. Numerical study on velocity-pressure field and wind forces for bluff bodies by k- $\varepsilon$, ASM and LES. Journal of Wind Engineering and Industrial Aerodynamics, 44 (1-3), 2841-2852

Murakami, S., 1993. Comparison of various turbulence models applied to a bluff body. Journal of Wind Engineering and Industrial Aerodynamics, 46 \& 47: 21-36.

Mochida A, Murakami S, Shoji M, Ishida Y. 1993. Numerical Simulation of flowfield around Texas Tech Building by Large Eddy Simulation. Journal of Wind Engineering and Industrial Aerodynamics, 46-47: 455-460.

Mochida, A.., Tominaga, Y., Murakami, S., Yoshie, R., Ishihara, T., Ooka, R., 2002. Comparison of various $\mathrm{k}-\varepsilon$ models and DSM applied to flow around a high-rise building-report on AIJ cooperative project for CFD prediction of wind environment. Wind and Structures, 5 (2-4), 227 244.

Mochida, A., Lun, I.Y.F. 2008. Prediction of wind environment and thermal comfort at pedestrian level in urban area. Journal of Wind Engineering and Industrial Aerodynamics, 96 (10-11), 1498-1527.

NEN., 2006. Wind comfort and wind danger in the built environment, NEN 8100 (in Dutch) Dutch Standard.

Nielsen, P.V., 1974. Flow in air-conditioned rooms. PhD Thesis, Technical University of Denmark, Copenhagen.

Nielsen P.V., 2004. Computational fluid dynamics and room air movement. Indoor Air, 14(Suppl. 7), 134-143.

Norton, T, Grant, J, Fallon, R, Sun, DW., 2009. Assessing the ventilation effectiveness of naturally ventilated livestock buildings under wind dominated conditions using computational fluid dynamics. Biosystems Engineering, 103 (1), 78-99.

Norton, T, Grant, J, Fallon, R, Sun, DW., 2010a. Optimising the ventilation configuration of naturally ventilated livestock buildings for improved indoor environmental homogeneity. Building and Environment, 45 (4), 983-995.

Norton, T, Grant, J, Fallon, R, Sun, DW., 2010a. Assessing the ventilation performance of a naturally ventilated livestock building with different eave opening conditions. Computers and Electronics in Agriculture, 71 (1), 7-21.

Nozu, T, Tamura, T, Okuda, Y, Sanada, S. 2008. LES of the flow and building wall pressures in the center of Tokyo. Journal of Wind Engineering and Industrial Aerodynamics, 96 (10-11), 17621773.

Oberkampf, W. L., Trucano, T. G., and Hirsch, C., 2004. Verification, validation, and predictive capability in computational engineering and physics. Applied Mechanics Reviews, 57 (5), 345 384.

Palyvos, J.A., 2008. A survey of wind convection coefficient correlations for building envelope energy systems' modelling. Applied Thermal Engineering, 28 (8-9), 801-808.

Pasquill, F., Smith, F.B., 1983. Atmospheric Diffusion, third ed. Ellis Horwood Ltd., Chichester, England.

Paterson, D.A., Apelt C.J., 1986. Computation of wind flows over three-dimensional buildings. Journal of Wind Engineering and Industrial Aerodynamics, 24: 192-213. 
Paterson, D.A., Apelt, C.J., 1989. Simulation of wind flow around three-dimensional buildings. Building and Environment, 24: 39-50.

Paterson, DA, Apelt, CJ,. 1990. Simulation of flow past a cube in a turbulent boundary layer. Journal of Wind Engineering and Industrial Aerodynamics, 35: 149-176.

Patnaik, G., Boris, J.P., Young, T.R., Grinstein, F.F., 2007. Large scale urban contaminant transport simulations with MILES. Journal Fluids Engineering, 129 (12), 1524-1532.

Persoon J, van Hooff T, Blocken B, Carmeliet J, de Wit MH. 2008. On the impact of roof geometry on rain shelter in football stadia. Journal of Wind Engineering and Industrial Aerodynamics, 96 (8-9), 1274-1293.

Price, C.A., 1975. The decay and preservation of natural building stone, Chemistry in Britain, 11 (10), 350-353.

Richards, P.J., Hoxey, R.P., 1993. Appropriate boundary conditions for computational wind engineering models using the k- $\varepsilon$ turbulence model. Journal of Wind Engineering and Industrial Aerodynamics, 46\&47: 145-153.

Richards, P.J., Mallison, G.D., McMillan, D., Li, Y.F., 2002. Pedestrian level wind speeds in downtown Auckland. Wind and Structures, 5 (2-4), 151-164.

Saathoff, P.J., Stathopoulos, T., Dobrescu, M., 1995. Effects of model scale in estimating pollutant dispersion near buildings. Journal of Wind Engineering and Industrial Aerodynamics, 54\&55: 549-559.

Saathoff, P., Stathopoulos, T., Wu, H., 1998. The influence of freestream turbulence on nearfield dilution of exhaust from building vents. Journal of Wind Engineering and Industrial Aerodynamics, 77-78: 741-752.

Saelens D, Carmeliet J, Hens H. 2003. Energy performance assessment of multiple-skin facades. $H V A C \& R$ Research, 9 (2), 167-185.

Sanders C., 1996. Heat, air and moisture transfer in insulated envelope parts: Environmental conditions. International Energy Agency, Annex 24. Final report, volume 2. Acco, Leuven.

Sasaki, R, Uematsu, Y, Yamada, M, Saeki, H. 1997. Application of infrared thermography and a knowledge-based system to the evaluation of the pedestrian-level wind environment around buildings. Journal of Wind Engineering and Industrial Aerodynamics, 67-68: 873-883.

Scaperdas, A. and Gilham, S., 2004. Thematic Area 4: Best practice advice for civil construction and HVAC, The QNET-CFD Network Newsletter, 2 (4), 28-33.

Scheffler, G.A., 2008. Validation of hygrothermal material modelling under consideration of the hysteresis of moisture storage, Ph.D. Thesis, Dresden, University of Technology, Dresden, Germany.

Schwarz, B., 1971. Die Wärme- und Stoffübertragung an Aussenoberflächen, Berichte aus der Bauforschung, 79, Wilhelm Ernst \& Sohn, Berlin, Germany.

Selvam, R.P., 1997a. Computation of pressure on Texas Tech University building using large eddy simulation. Journal of Wind Engineering and Industrial Aerodynamics, 67\&68: 647-657.

Selvam, R.P., 1997b. Numerical simulation of pollutant dispersion around a building using FEM. Journal of Wind Engineering and Industrial Aerodynamics, 67\&68: 805-814.

Sharples, S., 1984. Full scale measurements of convective energy losses from exterior building surfaces. Building and Environment, 19: 31-39.

Sharples, S. Charlesworth, P.S. 1998. Full-scale measurements of wind-induced convective heat transfer from a roof-mounted flat plate solar collector, Solar Energy, 62 (2), 69-77.

Shih, T.H., Liou, W.W., Shabbir, A., Zhu, J., 1995. A new k-e eddy-viscosity model for high Reynolds number turbulent flows: model development and validation. Computers \& Fluids, 24 (3), 227-238.

Smeaton, W.H., Lepage, M.F. and Schuyler, G.D., 1991. Using wind tunnel data and other criteria to judge acceptability of exhaust stacks. ASHRAE Transactions, 97 (2), 583-588.

Sorensen, DN, Nielsen, PV. 2003. Quality control of computational fluid dynamics in indoor environments. Indoor Air, 13 (1), 2-17.

Souster, C., 1979. A theoretical approach to predicting snow loads and driving rain deposition on buildings, Ph.D. Thesis, University of Sheffield, UK, 1979.

Srebric, J, Chen, Q, Glicksman, LR. 1999. Validation of a zero-equation turbulence model for complex indoor airflows. ASHRAE Transactions, 105 (2), 414-427.

Stathopoulos, T., Baskaran, A., 1990. Boundary treatment for the computation of 3D turbulent conditions around buildings. Journal of Wind Engineering and Industrial Aerodynamics, 35: 177200.

Stathopoulos, T., Baskaran, A., 1996. Computer simulation of wind environmental conditions around buildings. Engineering Structures, 18 (11), 876-885. 
Stathopoulos T., 1997. Computational wind engineering: Past achievements and computational challenges. Journal of Wind Engineering and Industrial Aerodynamics, 67-68: 509-532.

Stathopoulos, T., 2002. The numerical wind tunnel for industrial aerodynamics: real or virtual in the new millennium? Wind and Structures, 5 (2-4), 193-208.

Stathopoulos, T., Lazure, L., Saathoff, P., Wei, X., 2002. Dilution of exhaust from a rooftop stack on a cubical building in an urban environment. Atmospheric Environment, 36: 4577-4591.

Stathopoulos, T., Lazure, L., Saathoff, P., Gupta, A., 2004. The effect of stack height, stack location and rooftop structures on air intake contamination: a laboratory and full-scale study, Report R392, IRSST, Quebec.

Steeman, HJ, Janssens, A, Carmeliet, J, De Paepe, M. 2009a. Modelling indoor air and hygrothermal wall interaction in building simulation: Comparison between CFD and a well-mixed zonal model. Building and Environment, 44 (3), 572-583.

Steeman, HJ, Van Belleghem, M, Janssens, A, De Paepe, M. 2009b. Coupled simulation of heat and moisture transport in air and porous materials for the assessment of moisture related damage. Building and Environment, 44 (10), 2176-2184.

Steeman, HJ, Janssens, A, De Paepe, M., 2009c. On the applicability of the heat and mass transfer analogy in indoor air flows. International Journal of Heat and Mass Transfer, 52: 1431-1442.

Straube, JF, Burnett, EFP., 2000. Simplified prediction of driving rain on buildings. Proc. of the International Building Physics Conference, Eindhoven, The Netherlands, 18-21 September, 375382.

Stupart, A.W. 1989. A survey of literature relating to frost damage in bricks, Masonry International, 3 (2), 42-50.

Takakura, S, Suyama, Y, Aoyama, M. 1993. Numerical simulation of flowfield around buildings in an urban area. Journal of Wind Engineering and Industrial Aerodynamics, 46-47, 765-771.

Tamura, T, Kawai, H, Kawamoto, S, Nozawa, K, Sakamoto, S, Ohkuma, T., 1997. Numerical prediction of wind loading on buildings and structures - Activities of AIJ cooperative project on CFD. Journal of Wind Engineering and Industrial Aerodynamics, 67-68: 671-685.

Tamura, T, Nozawa, K, Kondo, K., 2008. AIJ guide for numerical prediction of wind loads on buildings. Journal of Wind Engineering and Industrial Aerodynamics, 96 (10-11), 1974-1984.

Tang, W, Davidson, CI., 2004. Erosion of limestone building surfaces caused by wind-driven rain. 2. Numerical modelling. Atmospheric Environment, 38 (33), 5601-5609.

Tominaga, Y., Murakami, S., Mochida, A., 1997. CFD prediction of gaseous diffusion around a cubic model using a dynamic mixed SGS model based on composite grid technique. Journal of Wind Engineering and Industrial Aerodynamics, 67-68: 827-841.

Tominaga, Y., Stathopoulos, T., 2007a. Numerical simulation of dispersion around an isolated cubic building - influence of turbulence models and turbulent Schmidt number. Proc. $12^{\text {th }}$ Int. Conf. Wind Engineering, Cairns, Australia.

Tominaga, Y., Stathopoulos, T., 2007b. Turbulent Schmidt numbers for CFD analysis with various types of flowfield. Atmospheric Environment, 41 (37), 8091-8099.

Tominaga, Y., Mochida, A., Murakami, S., Sawaki, S., 2008a. Comparison of various revised k- $\varepsilon$ models and LES applied to flow around a high-rise building model with 1:1:2 shape placed within the surface boundary layer. Journal of Wind Engineering and Industrial Aerodynamics, 96 (4), 389-411.

Tominaga, Y., Mochida, A., Yoshie, R., Kataoka, H., Nozu, T., Yoshikawa, M., Shirasawa, T., 2008 b. AIJ guidelines for practical applications of CFD to pedestrian wind environment around buildings. Journal of Wind Engineering and Industrial Aerodynamics, 96 (10-11), 1749-1761.

Tominaga, Y., Stathopoulos, T., 2008. Numerical simulation of plume dispersion around an isolated cubic buildings: comparisons between RANS and LES computations. BBAA VI International Colloquium on: Bluff Bodies Aerodynamics \& Applications, Milano, Italy, July, 20-24, 2008.

Tominaga Y, Stathopoulos T., 2009. Numerical simulation of dispersion around an isolated cubic building: Comparison of various types of k- $\varepsilon$ models. Atmospheric Environment, 43 (20), 32003210 .

Tominaga, Y., Mochida, A., Okaze, T., Sato, T., Nemoto, M., Motoyoshi, H., Nakai, S., Uematsu, T., Otsuki, M., 2010. Development of system for predicting snow distribution in built-up environment. The Fifth International Symposium on Computational Wind Engineering (CWE2010), Chapel Hill, North Carolina, USA, May 23-37.

Turner, D.B., 1970. Workbook of atmospheric dispersion estimates. Environmental Protection Agency, Environmental Health Series Air Pollution, 84. 
van Mook, F.J.R., 2002. Driving rain on building envelopes, Ph.D. thesis, Building Physics and Systems, Technische Universiteit Eindhoven, Eindhoven University Press, Eindhoven, The Netherlands, $198 \mathrm{p}$.

van Hooff, T, Blocken, B., 2010a. Coupled urban wind flow and indoor natural ventilation modelling on a high-resolution grid: A case study for the Amsterdam ArenA stadium. Environmental Modelling \& Software, 25 (1), 51-65.

van Hooff, T, Blocken, B., 2010b. On the effect of wind direction and urban surroundings on natural ventilation of a large semi-enclosed stadium. Computers \& Fluids, 39, 1146-1155.

van Hooff, T, Blocken, B., van Harten, M., 2010. 3D CFD simulations of wind flow and wind-driven rain shelter in sports stadia: influence of stadium geometry. Building and Environment,. In press. doi:10.1016/j.buildenv.2010.06.013

Vasilic-Melling, D., 1977. Three dimensional turbulent flow past rectangular bluff bodies, Ph.D. Thesis, Imperial College of Science and Technology, London.

Wang, X., 2006. Numerical simulation of wind-induced dispersion of emissions from rooftop stacks. M.A.Sc Thesis, Department of Building, Civil and Environmental Engineering, Concordia University, Montreal, Canada.

Westbury, P.S., Miles, S.D., Stathopoulos, T., 2002. CFD application on the evaluation of pedestrianlevel winds. Workshop on Impact of Wind and Storm on City Life and Built Environment, Cost Action C14, CSTB, June 3-4, Nantes, France.

White, R.B., 1967. The changing appearance of buildings, Her Majesty's Stationary Office, London, $64 \mathrm{p}$.

Willemsen, E., Wisse, J.A., 2007. Design for wind comfort in The Netherlands: Procedures, criteria and open research issues. Journal of Wind Engineering and Industrial Aerodynamics, , 95 (9-11), 1541-1550.

Wilson, D.J., Lamb, B., 1994. Dispersion of exhaust gases from roof level stacks and vents on a laboratory building. Atmospheric Environment, 28 (19), 3099-3111.

Wise, A.F.E., 1970. Wind effects due to groups of buildings. Royal Society Symposium Architectural Aerodynamics, London.

Wright, N.G., Easom, G.J., and Hoxey, R.J., 2001. Development and validation of a non-linear kepsilon: model for flow over a full-scale building. Wind and Structures, 4 (3), 177-196.

Wright, N.G., Hargreaves D.M., 2006. Unsteady CFD Simulations for natural ventilation. International Journal of Ventilation, 5 (1),13-20.

Wu, H.Q. and Stathopoulos, T., 1997. Application of infrared thermography for pedestrian wind evaluation, Journal of Engineering Mechanics - ASCE, 123 (10), 978-985.

Yakhot, V., Orszag, S.A., 1986. Renormalization group analysis of turbulence. Journal of Scientific Computing, 1 (1), 3-51.

Yamada, M, Uematsu, Y, Sasaki, R. 1996. A visual technique for the evaluation of the pedestrian-level wind environment around buildings by using infrared thermography. Journal of Wind Engineering and Industrial Aerodynamics, 65 (1-3), 261-271.

Yamada, T., 2010. Downscaling mesoscale meteorological models for computational wind engineering applications. The Fifth International Symposium on Computational Wind Engineering (CWE2010), Chapel Hill, North Carolina, USA, May 23-37.

Yang, Y., Gu, M., Chen, S., Jin, X., 2009. New inflow boundary conditions for modelling the neutral equilibrium atmospheric boundary layer in computational wind engineering. Journal of Wind Engineering and Industrial Aerodynamics, 97 (2), 88-95.

Yoshie, R., Mochida, A., Tominaga, Y., Kataoka, H., Harimoto, K., Nozu, T., Shirasawa, T., 2007. Cooperative project for CFD prediction of pedestrian wind environment in the Architectural Institute of Japan. Journal of Wind Engineering and Industrial Aerodynamics, 95 (9-11), 15511578. 


\section{Figure captions}

(a)

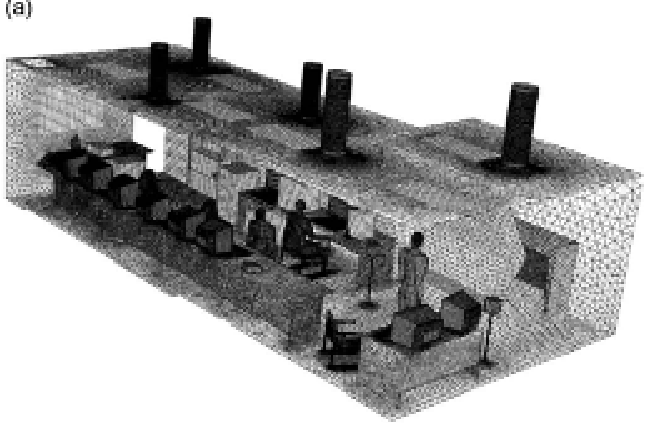

(b)

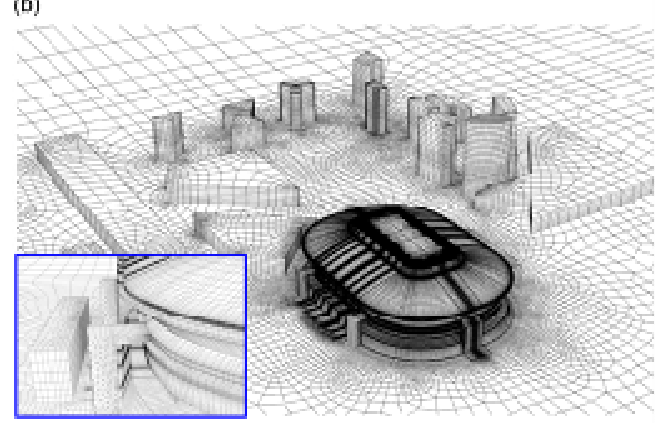

Figure 1. High-resolution computational grids for complex indoor and outdoor environments: (a) Unstructured body-fitted grid (3.7 million cells) for airflow simulation in a computer room (Abanto et al. 2004 - (C) Elsevier, reproduced with permission), (b) Hybrid body-fitted grid (5.6 million cells) for coupled urban wind flow and indoor natural ventilation of a multifunctional stadium (van Hooff and Blocken 2010a).

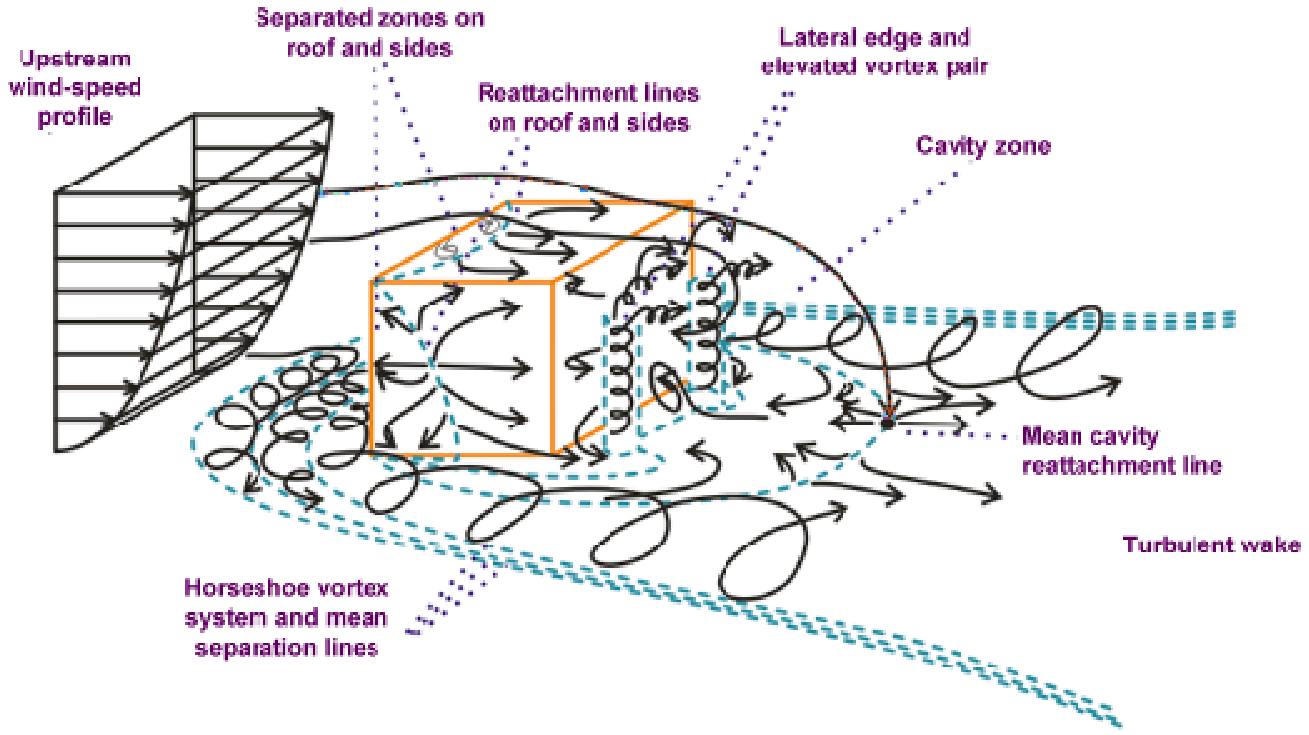

Figure 2. Schematic representation of the mean atmospheric boundary layer flow around an isolated sharp-edged low-rise building (modified from Hosker 1984). 
(a)

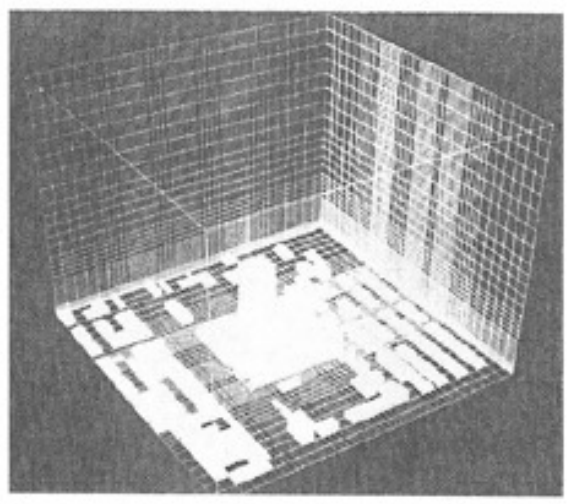

(c)

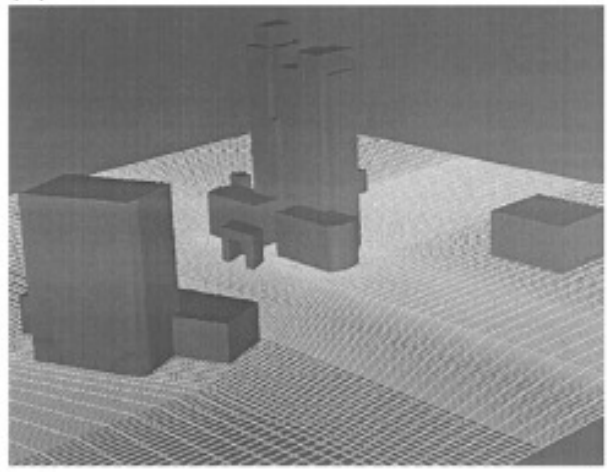

(e)

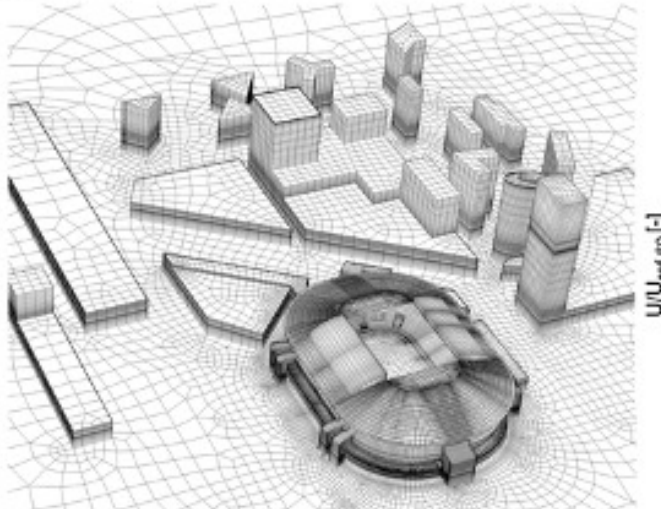

(b)

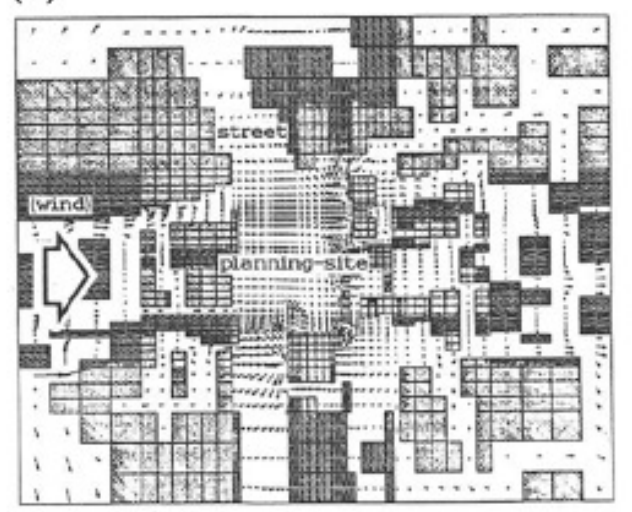

(d)

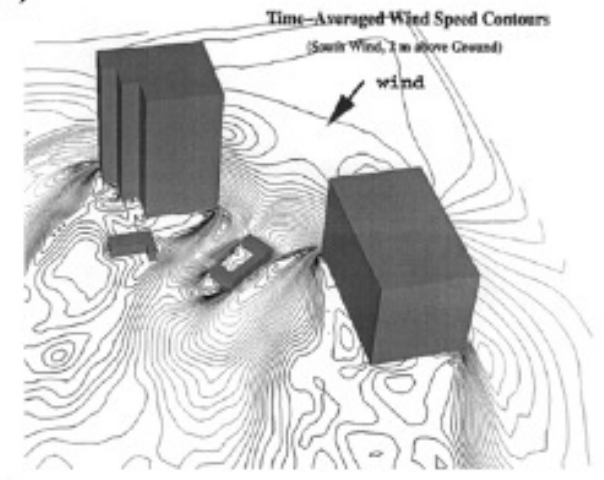

(f)

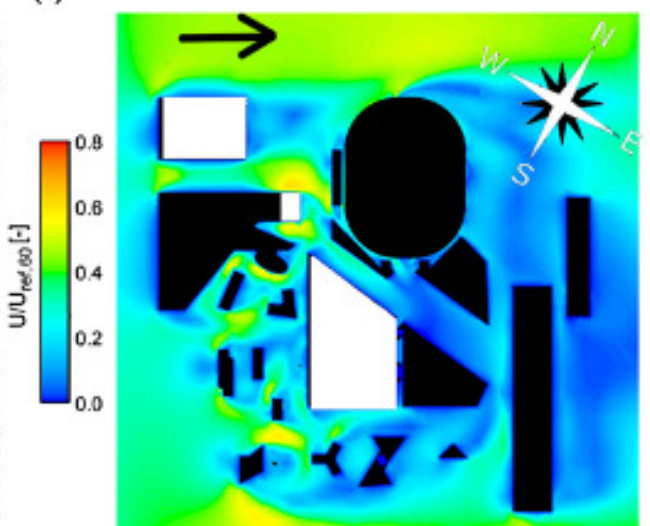

Figure 3. Examples of CFD studies of pedestrian-level wind environment in urban areas: (a-b) Grid (38895 finite elements) and wind-velocity vectors based on steady RANS simulations (Gadilhe et al. 1993 - (C) Elsevier, reproduced with permission), (c-d) Grid (total cell count unknown) and wind speed contours based on LES (He and Song 1999 - C Elsevier, reproduced with permission), (e-f) Grid (2.8 million cells) and wind speed ratio contours, based on steady RANS (Blocken and Persoon 2009). 
(a)
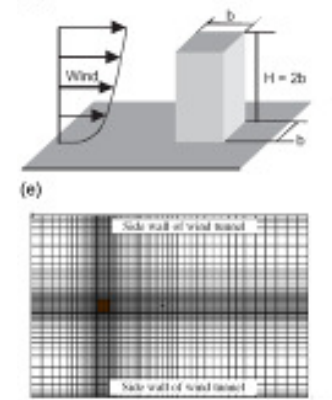
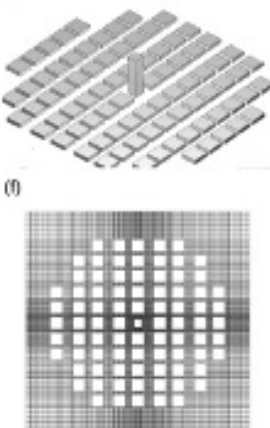

(c)

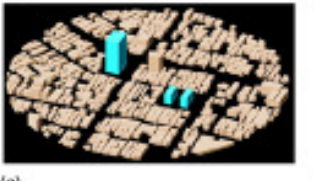

〈g)

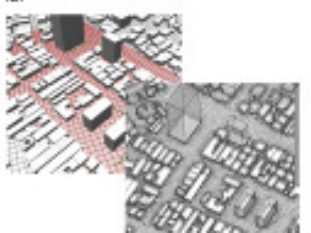

(6)
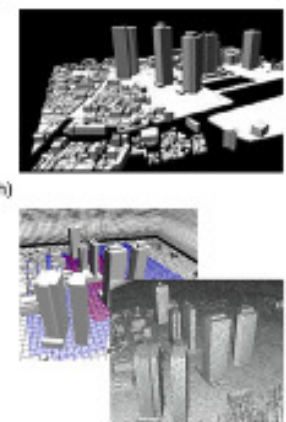

Figure 4. Building configurations in the validation studies by Yoshie et al. (2007), (a-b) Geometry and structured grid $\left(1.0 \times 10^{5}\right.$ cells) of isolated building, (c-d) Geometry and structured grid $\left(1.3 \times 10^{6}\right.$ cells) of high-rise building surrounded by low-rise buildings, (e-f) Geometry, immersed-boundary $(0.25$ million cells) and body-fitted ( 0.8 million cells) grids of building complex in actual urban area (Niigata), (g-h) Geometry, immersed-boundary (2.95 million cells) and body-fitted (1.18 million cells) grids of building complex in actual urban area (Shinjuku, Tokyo). Courtesy of R. Yoshie and Y. Tominaga (2010).

(a)

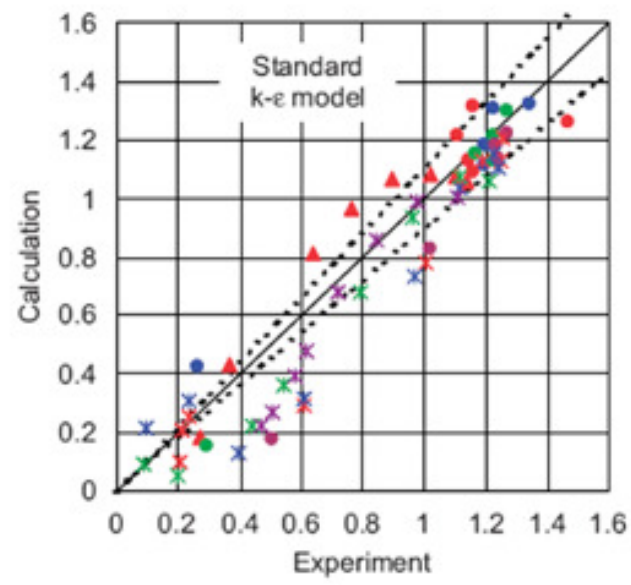

(b)

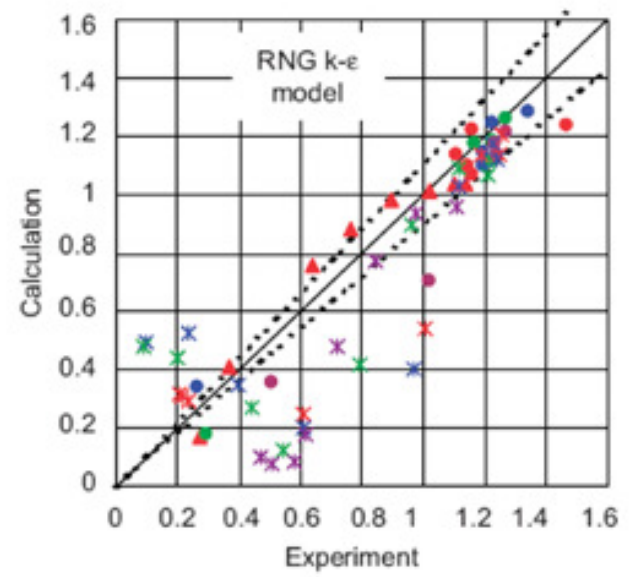

Figure 5. Comparison of CFD results and wind tunnel measurements of wind speed ratio for the isolated building (see Figure 4a) by Yoshie et al. (2007), (a) steady RANS with standard k- $\varepsilon$ model, (b) steady RANS with RNG k- $\varepsilon$ model. The symbols refer to: $\Delta=$ front of building; $\mathrm{o}=$ side of building; $\mathrm{x}$ $=$ behind building. The different colours refer to a variety of positions in front, beside and behind the building. 


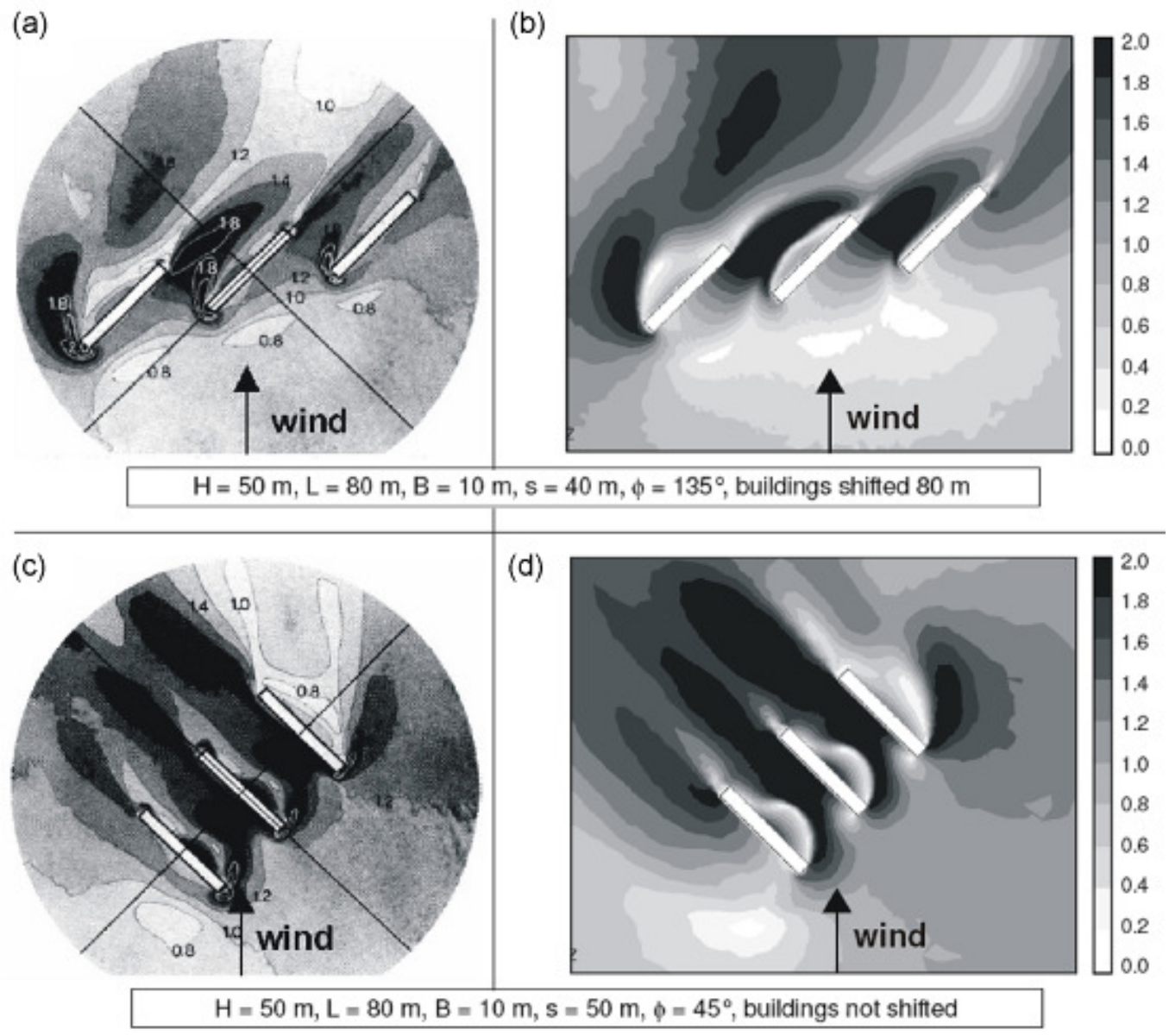

Figure 6. Validation study for parallel building configurations by Blocken and Carmeliet (2008), (a) Sand-erosion contour plots of the amplification factor $\mathrm{U} / \mathrm{U}_{0}$, (b) CFD results for $\mathrm{U} / \mathrm{U}_{0}(1.5$ million cells); (c) Sand erosion plots of $\mathrm{U} / \mathrm{U}_{0}$, (d) $\mathrm{CFD}$ results for $\mathrm{U} / \mathrm{U}_{0}$ ( 0.7 million cells). 
(a)

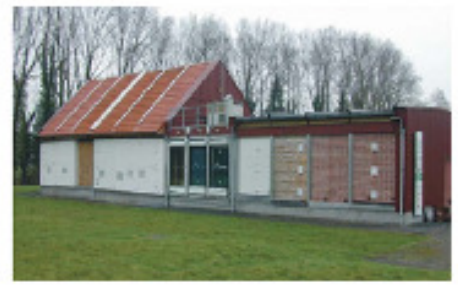

(c)

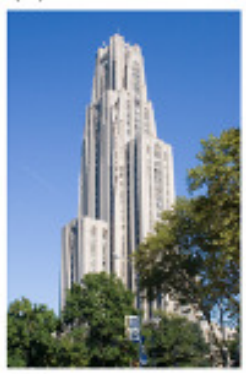

(f)

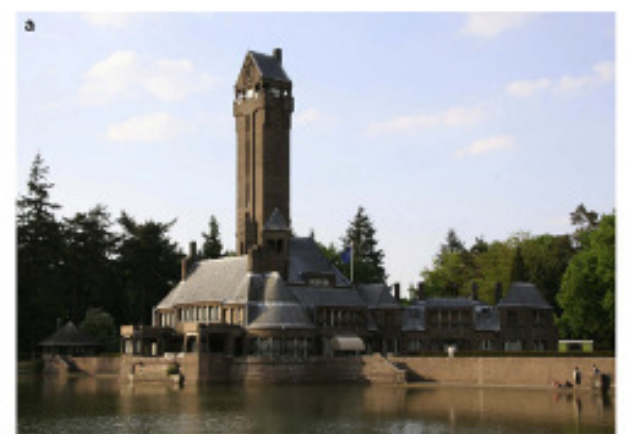

(d)

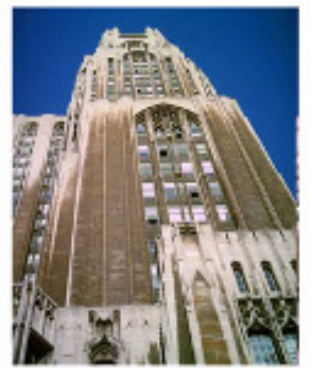

(1)

(e)

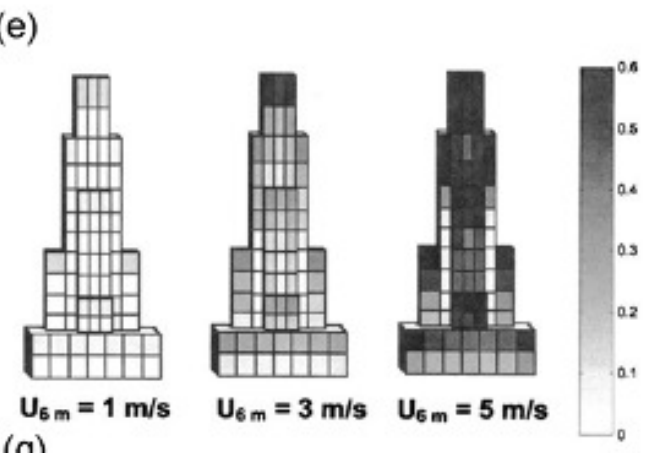

(g)

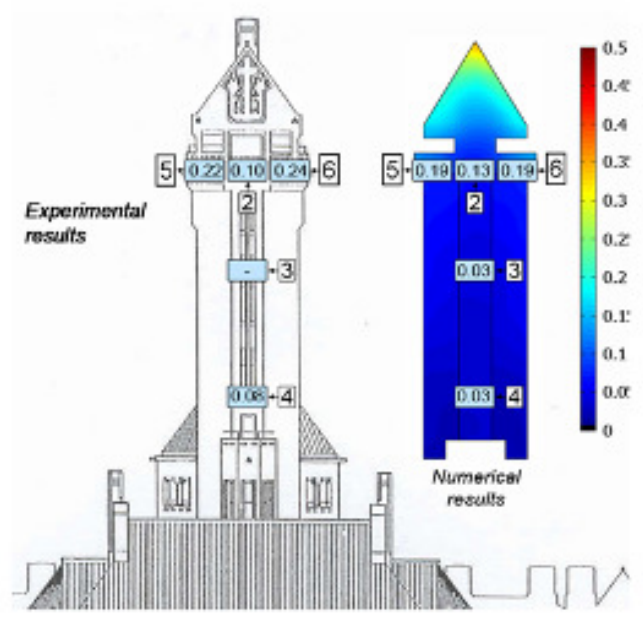

Figure 7. CFD validation studies of wind-driven rain on building facades. (a) VLIET test building in Leuven, Belgium (Blocken and Carmeliet 2005). (b) Catch ratio contours on the south-west facade after a rain event with south-west wind direction (Blocken and Carmeliet 2007b); (c) Cathedral of Learning; (d) Cathedral of Learning with surface soiling patterns (courtesy of Christopher Bailey 2010); (e) Catch ratios on the south-west facade for different reference wind speeds (Tang and Davidson 2004 - ( Elsevier, reproduced with permission); (f) Hunting Lodge St. Hubertus in the Netherlands, with indication of moisture related damage (Briggen et al. 2009); (g) Comparison of measured (left) and simulated (right) catch ratios at the end of a rain event with wind direction perpendicular to the facade (Briggen et al. 2009). 
(a)

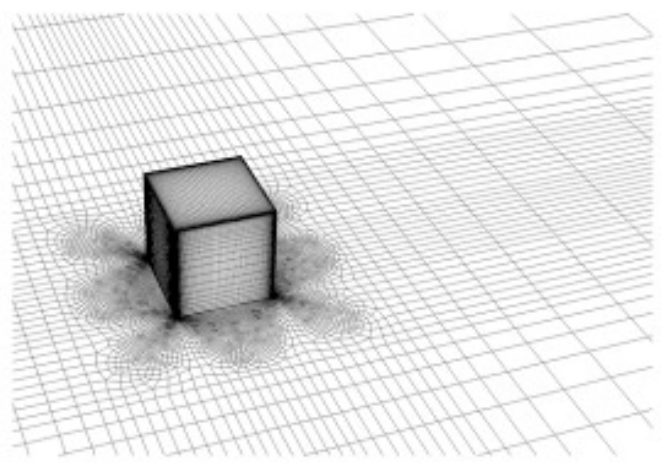

(b)

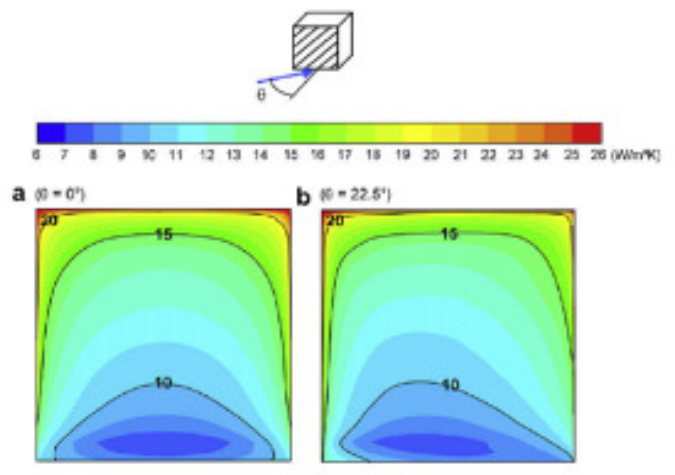

Figure 8. (a) High-resolution grid (1.9 million cells) for CFD simulation of convective heat transfer coefficients around an isolated cubic building model, with first grid cell point at $160 \mu \mathrm{m}$ from the facade; (b) forced convective heat transfer coefficients at the windward facade for a reference wind speed $\mathrm{U}_{10}=3 \mathrm{~m} / \mathrm{s}$ and $\theta=0^{\circ}$ and $22.5^{\circ}$ (Blocken et al. 2009).

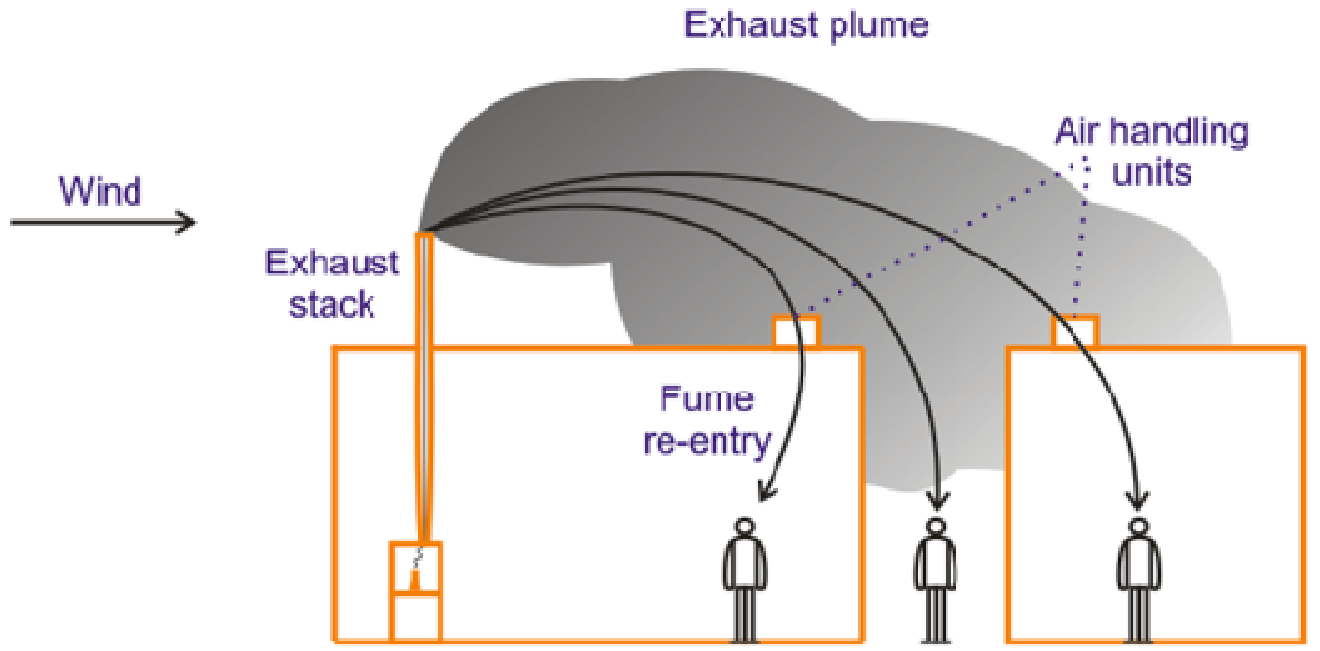

Figure 9. Schematic illustration of air pollutant dispersion problems: reingestion of exhaust into the same building or other buildings and accumulation in streets (modified from Petersen et al. 2002).

(a)

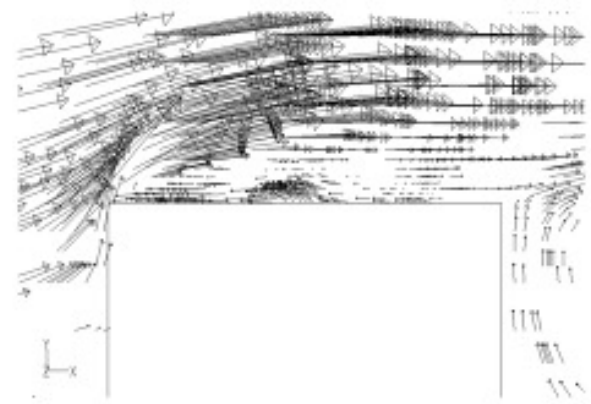

(b)

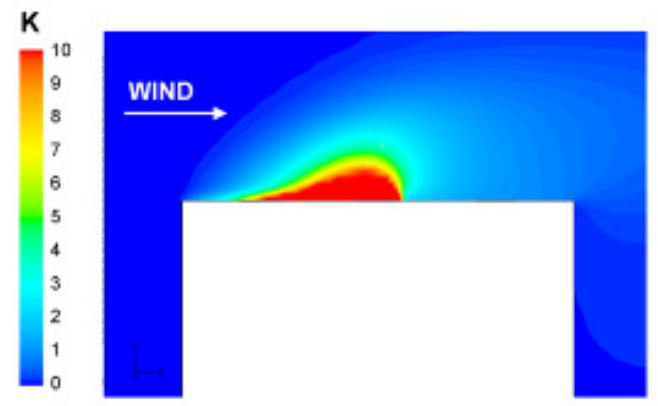

Figure 10. Vertical cross-section through vent in middle of roof. (a) Wind velocity vectors illustrating the escape of pollutants from the vent; (b) Dimensionless concentration coefficient K: the exhaust is trapped in the separation bubble and is advected upstream (results by the present authors). 
(a) Experiment

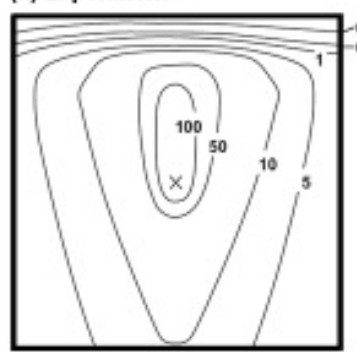

(d) RSM, Sc $=0.7$

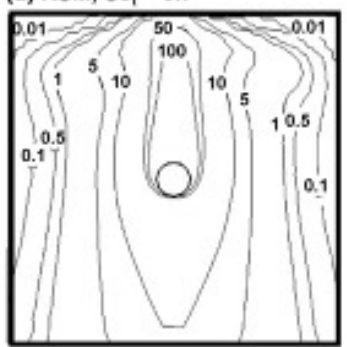

(g) RNG k-e, $\mathrm{Sc}_{\mathrm{t}}=\mathbf{0 . 7}$

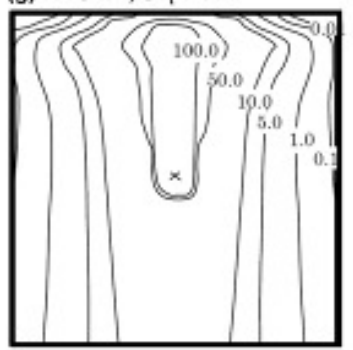

(b) Realizable $\mathrm{k}-\mathrm{z}, \mathrm{Sc}_{\mathrm{t}}=\mathbf{0 . 3}$

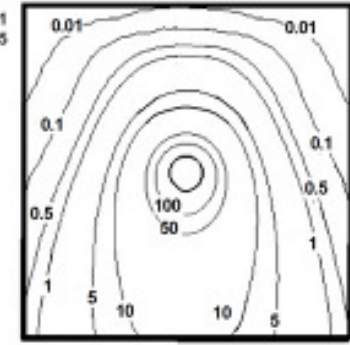

(e) Standard $\mathrm{k}-\mathrm{e}, \mathrm{Sc}_{1}=\mathbf{0 . 7}$

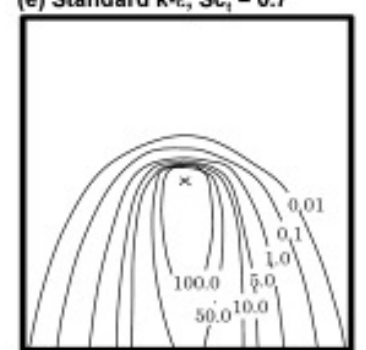

(h) Realizable k-e, $\mathrm{Sc}_{\mathbf{1}}=\mathbf{0 . 3}$

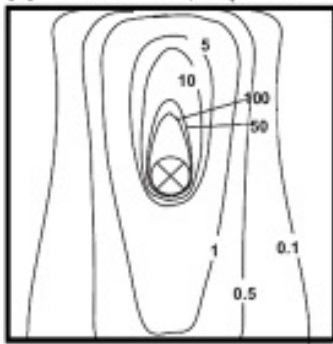

(c) RSM, Sc, $=0.3$

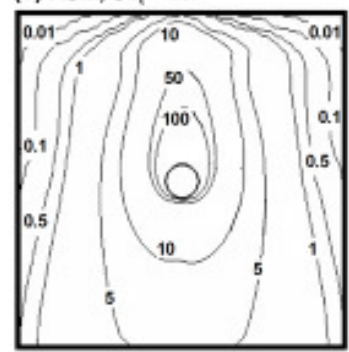

(f) Realizable $\mathrm{k}-\mathrm{e}, \mathrm{Sc}_{\mathrm{t}}=0.7$

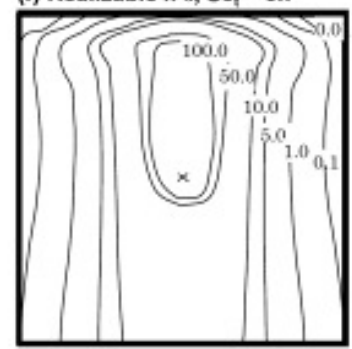

(i) LES, $\mathrm{C}_{\mathrm{s}}=0.12$

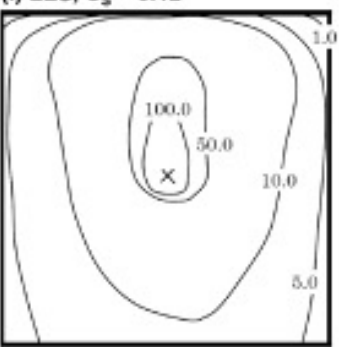

Figure 11. Contours of dimensionless concentration coefficient $\mathrm{K}$ on the cubic building roof: (a) wind tunnel measurements (Li and Meroney 1983); (b-i) CFD results by: (b-d) Wang (2006); (e-g) Tominaga and Stathopoulos (2007a); (h) Blocken et al. (2008a); (i) Tominaga and Stathopoulos (2008). Results are presented for different turbulence models and/or turbulent Schmidt numbers $\mathrm{Sc}_{\mathrm{t}}$. $\mathrm{C}_{\mathrm{S}}$ is the Smagorinsky constant. 